Review Article

\title{
Cardiac Progenitor Cells and the Interplay with Their Microenvironment
}

\author{
Arianna Mauretti, ${ }^{1,2}$ Sergio Spaans, ${ }^{1,2}$ Noortje A. M. Bax, ${ }^{1,2}$ Cecilia Sahlgren, ${ }^{1,2,3,4}$ and \\ Carlijn V. C. Bouten ${ }^{1,2}$ \\ ${ }^{1}$ Department of Biomedical Engineering, Eindhoven University of Technology, P.O. Box 513, 5600 MB Eindhoven, Netherlands \\ ${ }^{2}$ Institute for Complex Molecular Systems, Eindhoven University of Technology, Eindhoven, Netherlands \\ ${ }^{3}$ Faculty of Science and Engineering, Åbo Akademi University, 20520 Turku, Finland \\ ${ }^{4}$ Turku Centre for Biotechnology, Åbo Akademi University and University of Turku, 20520 Turku, Finland
}

Correspondence should be addressed to Carlijn V. C. Bouten; c.v.c.bouten@tue.nl

Received 31 March 2017; Accepted 26 July 2017; Published 17 September 2017

Academic Editor: Sari Pennings

Copyright (C) 2017 Arianna Mauretti et al. This is an open access article distributed under the Creative Commons Attribution License, which permits unrestricted use, distribution, and reproduction in any medium, provided the original work is properly cited.

\begin{abstract}
The microenvironment plays a crucial role in the behavior of stem and progenitor cells. In the heart, cardiac progenitor cells (CPCs) reside in specific niches, characterized by key components that are altered in response to a myocardial infarction. To date, there is a lack of knowledge on these niches and on the CPC interplay with the niche components. Insight into these complex interactions and into the influence of microenvironmental factors on CPCs can be used to promote the regenerative potential of these cells. In this review, we discuss cardiac resident progenitor cells and their regenerative potential and provide an overview of the interactions of CPCs with the key elements of their niche. We focus on the interaction between CPCs and supporting cells, extracellular matrix, mechanical stimuli, and soluble factors. Finally, we describe novel approaches to modulate the CPC niche that can represent the next step in recreating an optimal CPC microenvironment and thereby improve their regeneration capacity.
\end{abstract}

\section{Introduction}

Cardiac tissue is a composite material consisting of contractile and supportive cells surrounded by extracellular matrix (ECM) and is intertwined with nervous and vascular networks. An ischemic event, such as a myocardial infarction (MI), not only induces cell death but also affects the tissue structure and composition. This can eventually lead to loss of cardiac function due to changes in the key players of the cardiac microenvironment: (1) stem/ progenitor cells and supporting cells, (2) extracellular matrix (ECM) proteins, (3) the mechanical environment of the cells and the matrix, such as the cyclic strain provided by the beating heart, and (4) soluble factors, such as oxygen and cytokines (Figure 1(a)). In this review, we omit to describe vascular components, innervation, and electrical conduction, as these are extensively reviewed elsewhere [1-3], although their derivatives, such as oxygen gradients and cyclic strain, are included.

The myocardium shows very limited self-renewal; nevertheless, the notion of the heart as a terminally differentiated organ, incapable of regenerating after injury, has been challenged by abundant evidence in the last decade $[4,5]$. There is ongoing debate over whether cardiac regeneration is to be attributed to dedifferentiation and proliferation of cardiomyocytes $[6,7]$ or to differentiation of cardiac stem or progenitor cells [8-10], which makes it difficult to identify the ideal therapeutic target. Nevertheless, the existence of resident cardiac progenitor cells (CPCs) in the heart and their relevance for cardiac regeneration have been demonstrated by several studies [10-13]. CPCs have emerged as a promising candidate for cardiac regeneration, due to their differentiation potential $[10,14]$ and the ability to produce and remodel ECM proteins [15]. Moreover, after acute MI, 


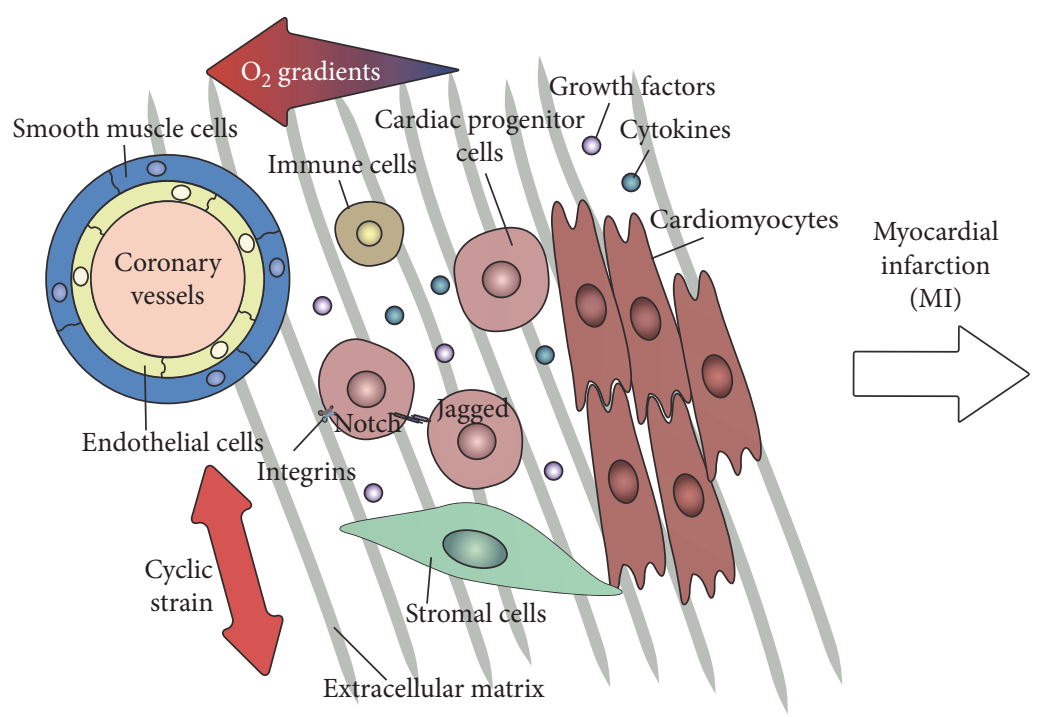

(a) Healthy cardiac microenvironment

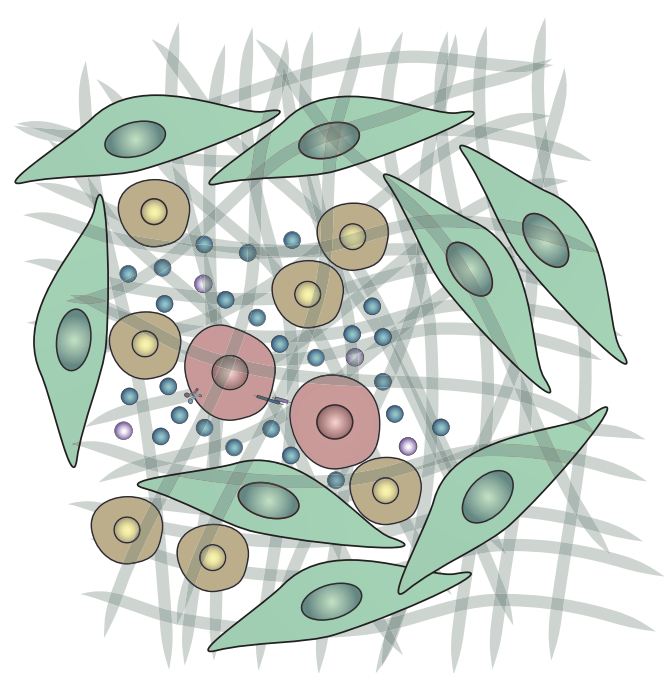

(b) Diseased cardiac microenvironment

FIGURE 1: The cardiac progenitor cell resident microenvironment. (a) The simplified representation shows some of the key players of the healthy CPC niche: (1) cellular elements (CPCs and supporting cells: cardiomyocytes, endothelial cells, smooth muscle cells, stromal cells, and immune cells) and cell-cell interactions such as signaling via Notch; (2) extracellular matrix (ECM); (3) mechanical stimuli, such as the cyclic strain provided by the beating heart; and (4) soluble factors, such as cytokines, oxygen gradients, and growth factors. (b) Simplified representation of the infarcted heart, where the microenvironment is altered and the niche components modified: (1) cardiomyocyte death and infiltration of myofibroblasts and immune cells; (2) excessive and disordered formation of ECM; (3) increased ECM stiffness and thus altered mechanical behavior; and (4) increased secretion of growth factors and cytokines.

the number of CPCs in the adult increases and differentiation into the cardiac lineages takes place [6]. However, the postMI microenvironment can affect CPC behavior: in chronic infarcts, CPCs are characterized by decreased telomerase activity, leading to impaired cell division and cellular senescence, as well as increased CPC apoptosis [6].

The traditional cell therapy approach to treat a MI entails isolation of CPCs, their expansion in vitro, and transplantation into the infarcted area [16]. Despite the immediate benefits on cardiac function, this treatment has shown very limited improvement on the long term [17-19], mainly due to low cell survival and engraftment in the host tissue [20]. In fact, a MI creates a hostile environment for the injected progenitor cells, due to the inflammatory response and tissue alterations, such as scar tissue formation, triggered by the cardiac injury, as extensively described elsewhere [20-22] (Figure 1(b)).

In the adult, stem or progenitor cells reside in specific microenvironments, referred to as "niches," that protect stem cells and regulate their fate and functions [23-25]. Stem cell niches are stored in specific anatomical compartments, located in tissue areas that are shielded from external damaging stimuli $[23,26]$.

In the adult mouse heart, putative progenitor cell niches have been identified in the atria, base-mid region, and apex [27]. To date, however, the cardiac progenitor cell niche is still largely uncharacterized and most studies have been performed on mouse models $[27,28]$.

For cell therapy, cells are isolated from their "resident niche" and expanded in an "in vitro niche," prior to transplantation into the "diseased niche" of the infarcted heart tissue (Figure 2(a)). An alternative to cell therapy is to promote the regeneration provided by endogenous CPCs, for instance by promoting the migration of CPCs to the damaged cardiac area (and to the "diseased niche"), as well as their proliferation and differentiation (Figure 2(b)). Another potential approach is to generate new, or engineered, microenvironments for the cells, in order to recreate optimal conditions to enhance their regenerative potential. Currently, there is a lack of knowledge on the composition and similarities of these three niches and on the interplay between CPCs and the niche components.

Therefore, in this review, we highlight the key elements of all potential CPC niches and discuss the interplay between $\mathrm{CPCs}$ and the niche components. Improved knowledge on the CPC niches and the CPC-niche interactions will enhance our insight into CPC behavior and the influence of the niche on CPC regenerative capacity, which can ultimately help modulate the microenvironment to promote the regenerative potential of CPCs. In the last part of this review, we therefore provide an overview on recent advances in the field of engineered cardiac microenvironments, which can represent the next step in exploring and modulating the CPC niche and $\mathrm{CPC}$ behavior for cardiac repair.

\section{The Cardiac Resident Progenitor Cell}

The presence of CPCs in the fetal and adult heart in mammals (including humans) has been extensively described (reviewed by [11]). Yet, CPCs are not conclusively defined 


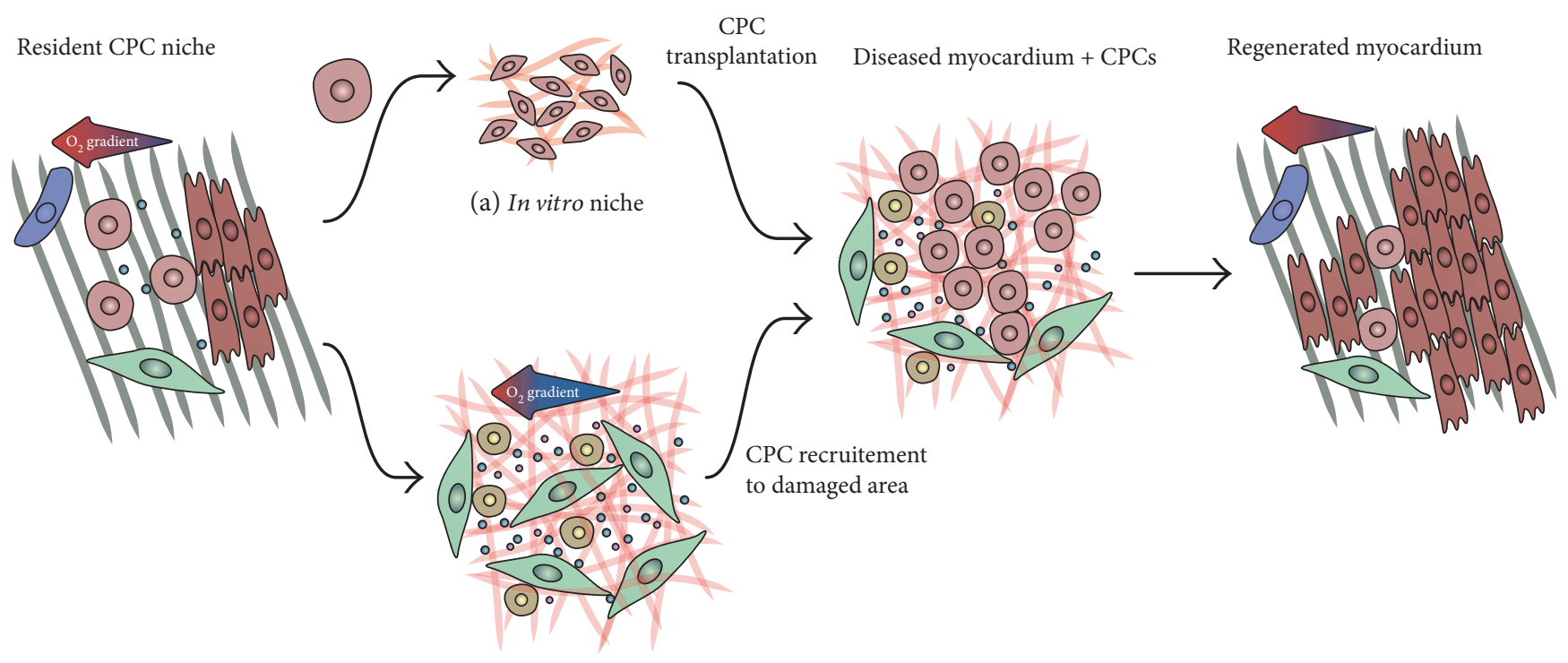

(b) Modulated local niche

FIgUre 2: The CPC microenvironments. For therapeutic application, CPCs can be isolated from their resident niche and (a) cultured in an in vitro niche, prior to transplantation into the infarcted heart, or (b) the local microenvironment can be modulated in order to recruit CPCs to the injured area. The aim of both approaches is to regenerate the myocardium thanks to CPC proliferation and differentiation into cardiomyocytes.

TABLE 1: Summary of the cardiac cell populations described in this review.

\begin{tabular}{|c|c|c|c|c|c|c|c|c|}
\hline \multirow{2}{*}{ Cell type } & \multicolumn{2}{|c|}{ Cardiac resident } & \multirow{2}{*}{ Self-renewal } & \multirow{2}{*}{ Multipotent } & \multirow{2}{*}{$\begin{array}{l}\text { Activation } \\
\text { after injury }\end{array}$} & \multirow{2}{*}{$\begin{array}{l}\text { Improvement of } \\
\text { cardiac function }\end{array}$} & \multirow{2}{*}{ Defined CPC } & \multirow{2}{*}{ [Refs] } \\
\hline & Embryonic & Adult & & & & & & \\
\hline Side population & + & + & + & + & + & + & Yes & {$[6,9,11,14,29-45]$} \\
\hline${\mathrm{c}-\mathrm{kit}^{+} \text {cells }}$ & + & + & + & + & + & + & Yes & {$[6,8-12,35,46-74]$} \\
\hline Sca-1 cells & + & + & + & + & + & + & Yes & {$[6,9-13]$} \\
\hline Isl1 progenitors & + & $?$ & + & + & $?$ & $?$ & No & {$[9,11,47,62,88-99]$} \\
\hline Cardiospheres & + & + & + & + & $?$ & ? & No & {$[9,11,47,62,87,88]$} \\
\hline
\end{tabular}

and the nomenclature stem/progenitor cell is often used in a generic sense. However, whereas "stem cells" replicate indefinitely and are pluripotent, "progenitor cells" can only divide a limited amount of times and are multipotent. To prevent misunderstanding, in this review, we propose a definition for CPC, based on key characteristics and functions of these cells. To be identified as a cardiac progenitor, a cell should (1) reside throughout the heart in both embryonic and adult stage and be (2) self-renewing and (3) multipotent, that is, able to differentiate in minimally three of the four cardiac cell types (cardiomyocytes, endothelial cells, smooth muscle cells, and fibroblasts). Furthermore, the cell should (4) be activated during cardiac injury and have regenerative potential proven by the fact that (5) transplantation of these cells into the diseased heart has favorable effects on cardiac function.

In this section, we will describe the populations of cells that we include among CPCs, as well as others that are often classified as CPCs but that we exclude from the CPC definition (Table 1), with a focus on their regenerative potential.
2.1. Cardiac Side Population Cells. The identification of cardiac progenitor cell population in the heart goes back to the beginning of the twenty-first century. Since 2002, several studies described the presence in the adult mouse heart of cardiac side population cells (cSPCs) [29-32], which were later identified also in fetal and adult hearts of rats and humans [33-35].

In vitro studies have proven the ability of these cells to self-renew with retained side population phenotype $[14,30,32,36]$, as well as their multipotency. Differentiation potential into cardiomyocytes $[14,33,37-40]$, endothelial cells $[36,39,41]$, and smooth muscle cells [39] was confirmed by transplantation studies into the injured heart $[31,33,41]$. Differentiation of side population cells into fibroblasts has so far only been shown after transplantation into the cryoinjured rat heart [33].

cSPCs are activated in murine injured hearts [42, 43], and more clinically relevant, they were also activated in human hearts in response to injury $[6,38,44]$. The regenerative potential of the cardiac side population was tested in 
three transplantation studies in animal models of cardiac injury. Only one of the performed transplantation studies $[30,31,33]$ assessed the functional recovery, reporting increase of injection fraction [30].

2.2. ${\mathrm{c}-\mathrm{kit}^{+}}^{+}$and Sca- $\mathrm{I}^{+}$Cardiac Cells. While no single marker exclusively identifies CPCs, there is a strong agreement that specific surface markers, like type III tyrosine kinase receptor c-kit (CD117) and Sca-1, identify cardiac progenitor populations. During early development, both markers are primarily haematopoietic stem cell markers present in the bone marrow. In 2003, both cells types were identified in the myocardium of adult rodents $[10,45]$. These cell populations are heterogeneous and thereby share similarities but are also distinct, although it is suggested that they both originate from the same resident precursor cell [46].

2.2.1. $\mathrm{c}^{-\mathrm{kit}^{+}}$Cardiac Cells. c-kit ${ }^{+}$cardiac resident progenitor cells are probably the most studied CPC population. Following the discovery in 2003, the presence of c-kit ${ }^{+}$ cells was confirmed not only in human [47] and mouse [48-50] from the developing to adult heart [51-54] but also in other mammals, including dog [55], pig [56], and sheep [57].

Self-renewal of c-kit ${ }^{+} \mathrm{CPCs}$ has been assessed in vitro $[45,47,55]$, and c-kit ${ }^{+}$cells appear to be the most undifferentiated progenitor population [58]. Despite controversy about the multipotency of c-kit ${ }^{+}$CPCs [46], several in vitro approaches revealed differentiation potential towards all four cardiac cell types, although the extent of differentiation is species- and developmental stage-dependent $[10,35,47,50$, $55,59,60]$. In fact, transplantation studies showed that c-kit ${ }^{+}$CPCs are more prone to differentiate toward endothelial and smooth muscle cells rather than cardiomyocytes and fibroblasts $[8,45,50,61]$. This suggests that fetal and neonatal-derived c-kit ${ }^{+}$CPCs only have potential to differentiate into cardiomyocytes, while adult-derived cells are more predisposed to differentiate into vascular cells only $[48,62]$.

A number of studies have verified the presence of c-kit ${ }^{+}$ cells in hypertrophic adult human hearts [12], after myocardial infarction $[6,50,53,63]$ and after ischemia/reperfusion injury $[64,65]$. In chronic heart failure, both increases and decreases in cell numbers have been described $[6,66,67]$.

Transplantation of adult c-kit ${ }^{+}$cells in preclinical studies in rodents revealed that attenuation of scar formation and left ventricular function [47, 68-70] was mainly induced by a paracrine mechanism. Although more preclinical research is needed to fully understand the contribution of c-kit ${ }^{+}$cells to cardiac regeneration, the first clinical trial of Cardiac Stem Cell Infusion in Patients with Ischemic Cardiomyopathy (SCIPIO, NCT00474461) was conducted [71, 72]. The data of this randomized phase 1 trial reported the induction of myocardial regeneration by c-kit ${ }^{+}$cells [72-74]. Despite the limited number of patients and the lack of placebo controls in this randomized phase 1 trial, as well as the expression of concern by The Lancet, both preclinical and clinical outcomes suggest a contribution of ${\mathrm{c}-\mathrm{kit}^{+}}^{+}$cells to cardiac repair.
2.2.2. Sca- $1^{+}$Cardiac Cells. Resident Sca- $1^{+}$cells are found in fetal and adult mouse and human hearts, in the atria, the intra-atrial septum, the myocardium, and the epicardium $[10,12,54,73,74]$.

Human $\mathrm{Scal}^{+}$cells harbor telomerase activity, which characterizes their proliferative potential and their ability to self-renew $[73,75,76]$. They display a mesenchymal profile and have gene expression comparable with ${\mathrm{c}-\mathrm{kit}^{+}}^{+}$cells, although murine $\mathrm{Sca}-1^{+}$CPCs have shown the highest correlation with cardiomyocytes and thereby seem to be the most committed to cardiomyogenic differentiation [58]. Culture-expanded Sca- $1^{+}$cells can be differentiated into cardiomyocytes in the presence of oxytocin or 5-azacytidine treatment $[13,75,76]$, and the cardiac differentiation potential is enhanced by addition of transforming growth factor-beta (TGF- $\beta$ ) [75, 76]. Next to cardiomyocytes, Sca- $1^{+}$cells can differentiate into endothelial cells and smooth muscle cells, as observed both in vitro $[10,74,75,77]$ and in vivo. Transplantation of isolated adult murine Sca- $1^{+}$ induced revascularization and revealed differentiation into cardiomyocytes and endothelial cells in infarcted mouse

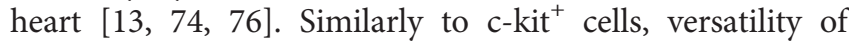
differentiation of $\mathrm{Scal}^{+}$cells is developmental stage- and subpopulation-dependent. Whereas fetal cells are very suitable for cardiomyogenic and angiogenic development, adult cells prefer smooth muscle cell differentiation [78].

As for cSPCs and c-kit ${ }^{+}$cells, Sca- $1^{+}$cells are present in the hypertrophic human heart [12] and the number of resident cells is expanding after myocardial infarction [74]. Transplantation of both fetal and adult Sca- $1^{+}$cells, of both murine or human origin, into the mouse injured heart limits structural and functional deterioration and thereby attenuates impairment of contractility. This regenerative potential is mediated by differentiation of Sca- $1^{+}$cells and via paracrine mechanisms $[74,76,79,80]$.

Despite these functional benefits of Sca- $1^{+}$cells in vivo, no clinical trials are conducted. The fact that there is no Sca-1 homologue present in the human genome raises questions about the epitope on human Sca- $1^{+}$CPCs that is recognized, which hampers their clinical application [81]. Interestingly, a panel of antibodies has recently been published that were specifically raised against resident human Sca- $1^{+}$CPCs. These antibodies, such as mAb C19, recognize CPCs in human heart tissue, and isolated $\mathrm{C} 9^{+}$cells have CPC characteristics and differentiate into the same lineages as Sca- $1^{+}$CPCs. This discovery might be a step forward for the application of these human CPCs in clinical trials [82].

2.3. Isl1 ${ }^{+}$Cell and Cardiospheres. Other cardiac cell types are often included among putative CPCs, such as $\mathrm{Isl}^{+}$cells and cardiospheres $[46,60,83-86]$. These cells reside in the heart; however, they do not (yet) respond to our definition of CPCs. Hereafter, we report what is known about $\mathrm{Isl}^{+}$cells and cardiospheres and explain why we excluded them from the CPC classification.

2.3.1. Is $\mathrm{I}^{+}$Progenitors. LIM-homeodomain transcription factor Isl1 positive cardiac cells share many of the characteristics of the CPCs described so far. $\mathrm{Isl}^{+}$cells are present in 
the developing heart [87], and the number of $\mathrm{Isl}^{+}$cells residing in the heart is substantially decreasing from fetal to neonatal and adult stages [62,87-91]. Their distribution is comparable with Sca- $1^{+}$cells; the location is conserved between rodents and human [90]. Postnatal Isl1 $1^{+}$cells can proliferate on cardiac mesenchymal feeders $[85,92,93]$, and they have been shown to differentiate into cardiomyocytes, endothelial cells, and smooth muscle cells [85, 90, 94]. Recently, local upregulation of $\mathrm{Isl}^{+}{ }^{+}$after ischemia/reperfusion in the adult mouse heart has been observed [95]. However, at the moment, there is no evidence of the regenerative potential of these cells, due to a lack of data regarding the beneficial effects on cardiac function after transplantation into the diseased heart. Nevertheless, there is interest in their therapeutic value, as shown by a clinical trial designed by Assistance Publique-Hôpitaux de Paris (NCT02057900).

2.3.2. Cardiospheres and Cardiosphere-Derived Cells. Often included also among CPCs are cardiospheres and cardiosphere-derived cells, first described by Messina et al. in 2004 [96]. Cardiospheres can be obtained from human atrial or ventricular biopsies from embryonic, fetal, and postnatal mouse hearts [96-98]. Cells migrating from the tissue explants spontaneously form cardiac multicellular spheroids when cultured on poly-D-lysine-coated culture plates. The cell monolayer growing after seeding cardiospheres on fibronectin-coated culture plates is known as cardiosphere-derived cells [99]. Although they unquestionably reside in the heart, due to the methods used to obtain cardiospheres and cardiosphere-derived cells, the origin of these cells is difficult to determine. Although most cardiosphere-derived cells in culture are known to express the endoglin marker CD105 [98], this mesenchymal and hematopoietic marker is not exclusive and thus cannot be used to specifically define these cells in vivo as CPCs. Moreover, activation after injury cannot be proven due to the lack of a specific marker for these cells. Nevertheless, cardiospheres and cardiosphere-derived cells are selfrenewing and can form cardiomyocytes, endothelial cells, and smooth muscle cells $[96,98-100]$.

Cardiospheres contain a mixed cell population, including c-kit ${ }^{+}$cells as well as endothelial precursors and mesenchymal cells [99]. Moreover, the expression of ECM proteins and integrins, as well as the gradients of oxygen and nutrients that are thought to occur between the periphery and the core of the spheroid, makes cardiospheres an in vitro model mimicking the CPC niche $[99,100]$. As such, cardiospheres can be used to study the CPC-niche interactions in vitro, beside their potential therapeutic application.

Adult cardiospheres and cardiosphere-derived cells have proven to have beneficial effects on cardiac function in murine and porcine animal models [101-107], and these broadly positive findings have led to two clinical trials, CADUCEUS and ALLSTAR. The Cardiosphere-Derived Autologous Stem Cells to Reverse Ventricular Dysfunction (CADUCEUS, NCT00893360) trial is a phase I randomized study in which patients received cells three months after myocardial infarction [108]. Although the study was not powered, transplantation of cells was safe and led to reduction in infarct size and increase in area of viable myocardium, unfortunately without change in ejection fraction of the left ventricle $[108,109]$. The positive outcomes initiated the start of a follow-up phase II clinical trial-Allogenic Heart Stem Cells to Achieve Myocardial Regeneration (ALLSTAR) [110].

Above, we described the various populations of resident CPCs that have been identified in the heart. All these cells have a heterogeneous nature and although they express different markers, they might be more similar than they are different. It is even suggested that all these described CPCs represent the same population and that the difference lies in the method of determination or their differentiation stage [47]. It is therefore important to precisely characterize and purify the CPC population, and further research is required. Nonetheless, although CPCs might not be rigorously defined, these cells have potential in cardiac regeneration.

\section{The CPC Microenvironment}

The regenerative potential of the heart is determined not only by the characteristics of CPCs but also by the influence of the microenvironment on their functions. In this section, the key components of the CPC niche will be described. These are (1) cellular components, represented by supporting cells; (2) cyclic strain, as provided by the cardiac beating; (3) extracellular matrix, which provides both mechanical and biochemical stimuli; and (4) soluble factors (such as cytokines) and oxygen tension, which can play a pivotal role in determining stem cell behavior (schematically represented in Figure 1(a)).

3.1. Supporting Cells. In both healthy and diseased hearts, cells interact with each other directly via cell-cell contact or indirectly by the expression of paracrine factors (Figure 3 ). Interactions can be isotypic (same cell types) or heterotypic (cells of different phenotypes) and the crosstalk between different populations will affect not only the cardiac function but also the regenerative potential. These interaction processes are complex and mostly unknown in the CPC niche. The role of the direct contact between CPCs and supporting cells is difficult to unravel. Most knowledge is derived from in vitro experiments, and crosstalk outcomes are mainly based on paracrine effects. In this section, we will focus on the interactions of CPCs with supporting cells and their importance for cardiac repair.

3.1.1. Cardiomyocytes. In the first in vivo study about the cardiac niche and putative supporting cells, connexins and cadherins were detected in cellular contacts between CPCs and cardiomyocytes as well as between CPCs and fibroblasts $[27,47,111]$. However, these connections were not observed between CPCs and endothelial cells and between CPCs and smooth muscle cells [27]. Cardiomyocytes are able to transfer information to CPCs (and vice versa) through gap junctions. Coculture of CPCs with cardiomyocytes promotes their expansion and results in beating CPCs, together with expression of cardiomyocyte-specific proteins and well-organized sarcomeres $[14,37,90,96,112]$, a process probably regulated by TGF- $\beta[113,114]$ and indirectly via the Wnt/beta-catenin 


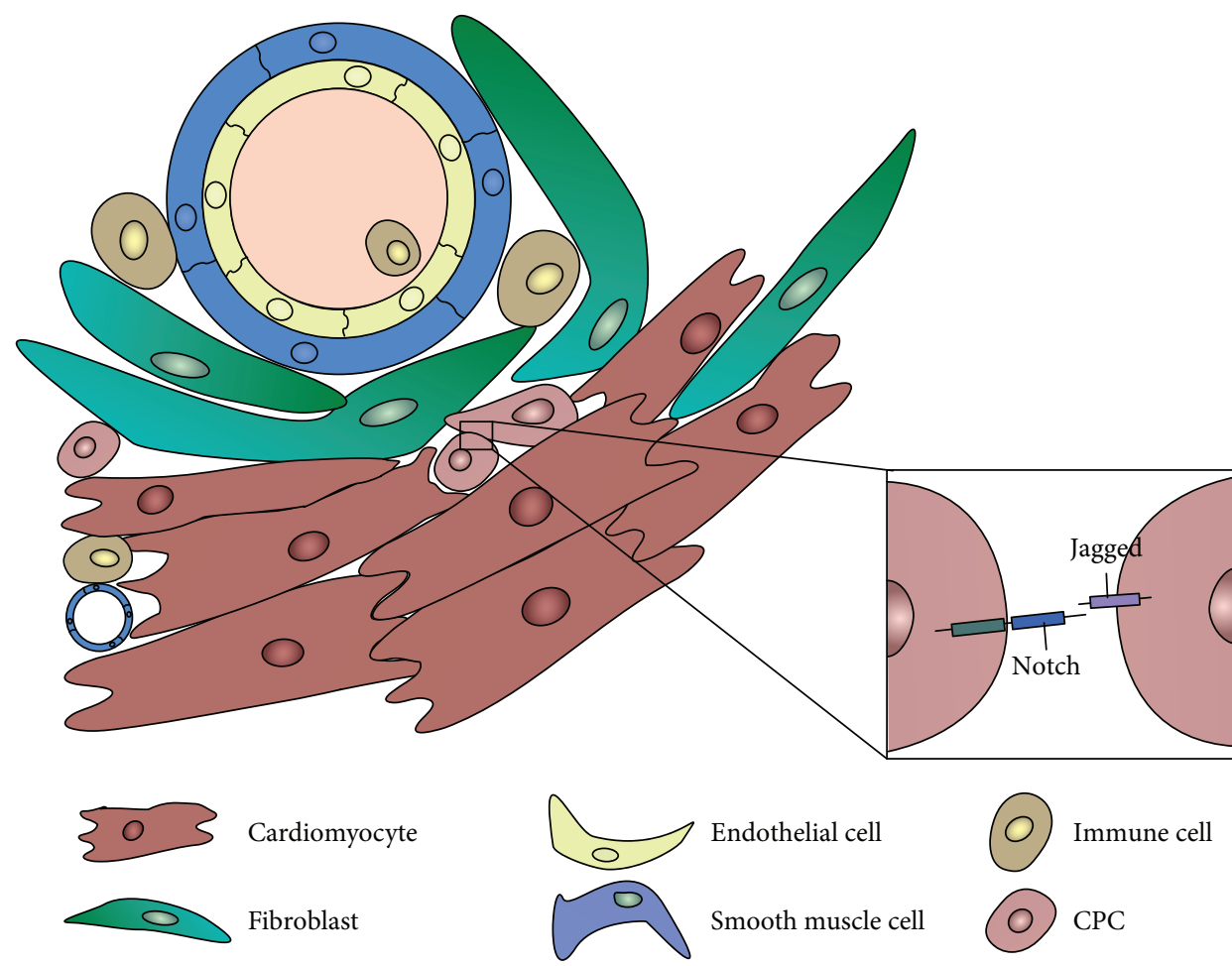

FIgure 3: Cell-cell interactions in the CPC niche. CPCs interact with each other and with supporting cells (cardiomyocytes, fibroblasts, endothelial cells, smooth muscle cells, and immune cells), both via direct cell-cell signaling (such as the Notch pathway) and paracrine signaling.

signaling system [115]. Therefore, coupling of CPCs with cardiomyocytes is critical to control the cardiac fate, and lack of appropriate interaction may hamper CPC differentiation [116]. However, cardiomyocytes might not solely stimulate differentiation toward the cardiomyogenic lineage. In fact, under hypoxia, cardiomyocytes produce vascular endothelial growth factors (VEGF), which might induce endothelial differentiation of the CPCs [115]. At the same time, CPCs can express growth factors and cytokines, which besides being necessary for their proliferation and senescence [117] are also important for cardiomyocyte proliferation, cell survival, and prevention of hypertrophy [118].

3.1.2. Endothelial Cells. Since CPCs are often found in the perivascular area, interaction with endothelial cells and smooth muscle cells is plausible, although cell-cell interactions were not observed [27]. It can be hypothesized that endothelial cell-CPC interaction is regulated via Notch, since Notch receptors are predominantly expressed by the vascular endothelium [119]. Notch signaling is crucial for cell fate decisions that underlie cardiomyogenic and vessel formation $[119,120]$. Since Notch signaling is a highly conserved pathway that acts via cell-cell contact, it will be discussed in more detail later on. Indirect interactions between endothelial cells and CPCs, via the production of VEGF, might not only promote CPC migration [121] but also regulate CPC differentiation towards endothelial or smooth muscle cells $[39,41]$.

3.1.3. Immune Cells. Myocardial injury causes inflammation by activation of immune cells, which are involved in cardiac repair as well as scar tissue formation. Hence, crosstalk between CPCs and immune cells is likely to take place, although there are no proven interactions. Transplantation studies revealed that CPCs are able to dampen the immune response and thereby influence cardiac repair [122]. However, the mechanisms underlying CPC modulation of the immune system are not completely unrevealed, as it is the case for mesenchymal stem cells [123-126].

(1) Macrophages. Macrophages are a heterogeneous population of both protective and cytotoxic cells. They play a cardioprotective role by maintaining cardiac homeostasis via interactions with other cardiac cells [127]. Macrophages are able to produce growth factors (e.g., IGF-1, VEGF, and TGF- $\beta$ ), which stimulates CPC proliferation and induces differentiation towards both cardiomyocytes and endothelial cells $[128,129]$. On the other hand, CPCs are able to polarize macrophages away from their proinflammatory phenotype, although the exact mechanism behind it is unclear. It is not known toward which cell type the polarization acts, although it was proven not to be toward the anti-inflammatory phenotype [130]. We therefore assume that a cardioprotective effect arises from the interaction between macrophages and CPCs.

(2) Natural Killer Cells. Natural killer cells, a subset of the innate lymphoid cell compartment, are effectors of the innate immune system, which are essential in allogeneic transplantation. Their cytotoxic effects are mediated by exocytosis of granules that perforate the target cell to trigger 
apoptosis [131]. Little is known about these cells and CPCs, but a recent study by Boukouaci et al. revealed that CPCs are protected from killer cell cytotoxicity within an inflammatory context [132]. On the other hand, CPCs are able to downregulate the toxicity of natural killer cells and bias cytokine secretion towards an anti-inflammatory state. Retention of CPCs is improved by this crosstalk with natural killer cells and contributes to cardiac regeneration [132].

(3) Mast Cells. Mast cells are bone marrow-derived precursors, and although their number increases in the failing heart, their exact role in cardiac disease and regeneration is understudied. Moreover, mast cells express similar markers as CPCs [133]. It is known that CPCs share distinct characteristics with mast cells, but not all CPCs are mast cells [133]. Both mast cells and CPCs are located in the perivascular area, although cell contact is not reported. Paracrine effects can be assumed since mast cells produce several cytokines, growth factors, and angiogenic factors that are all involved in cardiac repair [134]. During mast cell degranulation, TGF- $\beta$ is released, which as described earlier is important for CPC differentiation [135].

\subsubsection{Stromal Cells}

(1) Fibroblasts. Together with cardiomyocytes, fibroblasts were the first supporting cells of CPCs to be discovered $[27,47]$. Like cardiomyocytes, fibroblasts are connected to CPCs via gap and adherens junctions. Not only do fibroblasts maintain the supporting matrix of the CPC niche [115] (the importance of the ECM-cell interaction will be discussed later on in a dedicated paragraph), but they also might influence the differentiation potential of CPCs. It has recently been shown that fibroblast-conditioned medium can induce differentiation via the Wnt signaling pathway [136] and that fibroblasts produce angiogenic and antiangiogenic factors [115]. Fibroblasts originate mainly from the epicardium [137]; therefore, interactions between epicardium-derived cells (EPDCs) and CPCs need to be described.

(2) Epicardium-Derived Cells (EPDCs). CPCs are often found in the subepicardial region, which mostly consists of EPDCs. EPDCs have a crucial modulatory role during cardiac development, and their activation after injury [138-141] also suggests the same role in the adult heart [142]. Due to these characteristics, some groups even suggest that the epicardium is a source of progenitor cells [143, 144]. The presence of CPCs near the epicardium and EPDCs suggests that important interactions occur between CPCs and EPDCs. Previous research showed that EPDCs stimulate the migration and proliferation of CPCs $[141,145,146]$. Coculture of CPCs with EPDCs revealed induction of metalloproteinases and their inhibitors, which affected infarct size [146]. In fact, matrix remodeling is not only important to prevent cardiac dilation after injury, but it also plays a role in maintaining the supporting network of the CPC niche. Moreover, coculturing stimulated angiogenesis and thereby improved cardiac function. The interaction between CPCs and EPDCs is reciprocal and results in synergistic action, leading to improved cardiac function. This beneficial effect is at least partly explained by paracrine stimulation [146].

(3) Telocytes. Another stromal cell type which is present in the subepicardial region is the telocyte, formally known as interstitial Cajal-like cells [147]. Telocytes are in close vicinity with CPCs, and stromal synapses and adherens junctions are formed between the cells both in vitro and in vivo $[148,149]$. These adherens junctions not only control the retention of CPCs but also might be important for division and migration of CPCs [149]. Therefore, it is assumed that telocytes provide guidance and nursing for CPCs to stimulate their activation, proliferation, and differentiation leading to cardiac repair $[148,150,151]$. Furthermore, telocytes produce growth factors (e.g., VEGF) [152] and macromolecular signals, such as microRNAs [153], which might influence the differentiation potential of CPCs [151].

3.1.5. Cell-Cell Signaling via Notch in CPCs. Cell-cell contactdependent signaling is an essential component of the niche and has an important influence on cellular behavior. Notch signaling is a fundamental and highly conserved pathway that acts via direct cell-cell communication and has a key role in the heart. Notch regulates a number of cell functions, such as survival, proliferation, and differentiation, as well as tissue development and homeostasis. In mammals, four Notch proteins have been identified (Notch1-4), which can bind to ligands of the Delta or Serrate/Jagged families expressed by neighboring cells, as extensively reviewed elsewhere [154, 155] (Figure 3). Following cleavage by $\mathrm{y}$-secretase, Notch intracellular domain (NICD) is released and translocates to the nucleus, where it regulates the expression of target genes, such as members of the Hes and Hey families [154-156], as well as Nkx2.5 in cardiac cells [157].

Notch signaling represents an essential element of the cardiac microenvironment. Firstly, Notch plays a crucial role in cardiomyogenesis, and Notch mutations have been linked to several congenital heart and heart valve defects [154-156]. Active Notch signaling is needed for CPC differentiation [158], whereas in cardiomyocytes, Notch is activated during embryonic development $[155,159]$ and inactivated during maturation [160] and after birth (reviewed by [159]). Secondly, several studies demonstrated the reactivation of Notch in adult cardiomyocytes after MI, in small animal models [157] as well as in humans [161, 162]. This shows the key role of Notch in cardiomyocyte survival $[163,164]$ and cardiac repair after injury $[159,165]$.

In the adult mouse, about $60 \%$ of $\mathrm{c}-\mathrm{kit}^{+} \mathrm{CPCs}$ expresses the Notch1 receptor, and signaling with surrounding cells, either CPCs or myocytes, is mediated by Jagged1 [157]. Notch signaling strongly depends on timing and dosage $[166,167]$; it is needed for proliferation and expansion of the CPC pool [160] and is essential for CPC cardiomyogenic differentiation $[157,158]$. The activation of Notch1 by Jagged1 in mouse c-kit ${ }^{+}$CPCs promotes the nuclear translocation of N1ICD and enhances its colocalization with the cardiac transcription factor and Notch target gene Nkx2.5 [157]. However, Notch becomes undetectable when differentiating CPCs lose their proliferative capacity, showing 
that its downregulation is needed for terminal differentiation [160]. Moreover, overexpression of Notch1 in mouse c-kit ${ }^{+}$ CPCs leads to improved resistance to oxidative stress, and injection of these cells in mouse infarcted hearts resulted in an enhanced cardioprotective effect, as shown by smaller infarct length and area, functional improvement, and larger capillary density as compared to control cells (where endogenous Notch was activated via Jagged1) [120].

In view of these findings, Notch has been proposed as a potential therapeutic target for treating myocardial disease. Hydrogels functionalized with a peptide mimic of Jagged 1 were shown to activate Notch signaling in rat c-kit ${ }^{+} \mathrm{CPCs}$, and injection of CPCs embedded in these hydrogels led to improved cardiac repair in a mouse MI model [168].

Yet, very little is known about Notch in human CPCs. Recent studies, by our group and by others, have studied Notch signaling in cardiac progenitors cultured as multicellular spheroids, or cardiospheres (if isolated from adult myocardial tissue). The spheroid model better mimics the in vivo cell-cell interactions as compared to cell monolayers and therefore represents an interesting and promising model to study cell-cell signaling (see paragraph 4, "Approaches to modulating the CPC microenvironment"; [169]). The formation of cardiospheres from adult explant-derived cells increased the expression of Notch1 and Notch3 receptors [170]. Moreover, multicellular spheroid formation was shown to activate Notch signaling in both fetal and adult CPCs and more evidently so in combination with hypoxic culture, indicating the pivotal role of niche-like environmental conditions on a fundamental cellular pathway such as Notch signaling.

Understanding the role and activity of this key regulatory pathway in human endogenous CPCs will be crucial for the improvement of CPC-based cardiac regeneration therapies.

3.2. Extracellular Matrix. Cardiac cells are surrounded by a highly organized and dynamic network, known as the ECM that forms the cardiac tissue [171]. The cardiac ECM is composed of different proteins, proteoglycans, and glycosaminoglycans that form a fibrillar mechanical support in which cells are embedded. These structural components include collagen types I, III, and V, as well as elastin that provides resilience to the cardiac tissue [172-174]. Furthermore, proteoglycans such as tenascin- $\mathrm{C}$ and decorin contribute to the cardiac tissue and are crucial for the stability and integrity of the ECM $[175,176]$. Next to structural components, the ECM is composed of nonstructural elements that regulate important cellular functions, such as adhesion, proliferation, and differentiation. These are primarily type IV collagen, laminins, and fibronectin $[172,177]$. Moreover, within the ECM network, different cell types secrete soluble macromolecules in the extracellular space, such as VEGF, TGF- $\beta$, and stromal cell-derived factor $1-\alpha(\operatorname{SDF} 1-\alpha)$, which regulate and stimulate important cellular processes [178-180].

Cardiac fibroblasts are primarily responsible for the production and remodeling of ECM [181], both under healthy and under pathological conditions. During and following a myocardial infarction, fibroblasts become activated and secrete an abundance of ECM components to compensate for the loss of cardiomyocytes. Eventually, this leads to excessive ECM formation and scarring, with adverse effects on the contractility of the cardiac tissue. Altogether, this fibrotic environment might not be ideal for the injected progenitor cells. For this reason, the effect of the ECM environment on progenitor cell survival and function should be investigated to improve the CPC contribution to cardiac regeneration. Below, recent literature on the interaction of $\mathrm{CPCs}$ with native and/or synthetic ECM in vitro and in vivo is summarized and discussed, with a focus on ECM properties such as stiffness, architecture, and composition.

3.2.1. Integrins. CPC adhesion to its environment is essential for the connection between intracellular components and the ECM. Via focal adhesions (FAs), CPCs can sense their environment and respond accordingly. In general, FAs are transmembrane protein complexes that directly link ECM components or other cells to intracellular actin junctions, intermediate filaments, and sarcomeres [182]. Important components of these transmembrane proteins are integrins, which are heterodimers consisting of a combination of $\alpha$ and $\beta$ subunits. In mammals, 24 types of receptors can be formed and each combination has a specific binding affinity to a different ECM component. For CMs, the most occurring integrins are $\alpha 1 \beta 1, \alpha 5 \beta 1$, and $\alpha 7 \beta 1$, which bind specifically to collagen type I (COL), fibronectin (FN), and laminin (LN), respectively, with $\beta 1$ being the prevalent $\beta$ subunit [182]. Furthermore, the protein expression of different types of integrin also changes from neonatal CMs, where the dominant subunit is $\alpha 5$, to adult CMs, where the $\alpha 5$ is replaced by $\alpha 7$ subunit $[182,183]$. Similar changes in integrins expression can also be observed in response to pathological conditions [182]. Human fetal CPCs subjected to cardiomyogenic differentiation protocol in vitro showed unvaried expression but increased clustering of integrin $\beta 1$, indicating FA maturation and improved mechanosensing with early cardiac differentiation [184]. These studies underline the importance of integrins in the heart and suggest that the FA expression of CPCs and interactions with specific ECM components should also be studied to be able to guide CPCs towards specific lineages.

\subsubsection{CPC-ECM Interactions}

(1) ECM Composition. The versatility of interactions between CPCs and their direct surroundings generates the possibility to obtain highly regulated and regenerative cellular responses via intracellular signaling. It is currently known that the stiffness, composition, and/or structure of the natural ECM has an effect on progenitor commitment in vitro [185]. More importantly, the response that the ECM evokes on cells are different depending on the cell type. This has been tested by culturing cardiac progenitor cells on different substrates in vitro and studying the cellular behavior and functions associated with cardiac regeneration. The first studies were initiated by French et al., who studied c-kit ${ }^{+}$SpragueDawley rat CPC behavior, that is, cardiomyogenic gene expression, cell survival, and proliferation, cultured on decellularized porcine ventricular ECM (cECM) or standard 
collagen type I (COL), which more closely resembles the biochemical composition of a scar following a MI [186]. Interestingly, early cardiac genes for GATA-binding protein-4 (GATA-4), Nkx2.5, $\alpha$-myosin heavy chain, and troponin C and $\mathrm{T}$ were increased when CPCs were cultured for 2 days on cECM compared to COL. Moreover, fibroblast and endothelial/smooth muscle cell-specific genes decreased and remained constant, respectively, for CPCs cultured on cECM compared to COL. In a recent study, human Sca- $1^{+}$cells originating from either fetal heart (fCPCs) or adult hearts (aCPCs) were encapsulated and cultured in three-dimensional (3D) hydrogels consisting of either cECM or COL [187]. Similarly, gene expression of early cardiac markers, that is, GATA-4, Nkx2.5, myocyte enhancer factor $2 \mathrm{c}(\mathrm{Mef} 2 \mathrm{c})$, and myosin light chain 2v (MLC2v), increased when fCPCs and aCPCs were cultured in CECM compared to COL after 4 days. Furthermore, after 7 days, these markers increased when fCPCs were cultured in CECM and remained constant for aCPCs. One explanation for the minimal increase in cardiac markers after a longer period of time could be the development of an endogenous microenvironment by CPCs that decreases the early biochemical effect of cECM. Additionally, improved proliferation and survival was observed for both cECM-coated surfaces and for CPCs encapsulated in cECM hydrogels.

These findings indicate the importance of the biochemical composition for the early maturation of fCPCs towards cardiac specific lineages. Nevertheless, more information is needed on the specific ECM composition to be able to understand which of the components generates the beneficial response of CPCs towards cardiac-derived ECM, considering the fact that CPCs reside in a specific, yet complex, niche that strongly determines their behavior [27]. In a follow-up study by French et al., CPCs were cultured on cECM and were COL-, FN-, and LNfunctionalized. In a follow-up study by French et al., CPCs were cultured and subjected to different cyclic strains on Bioflex plates functionalized with cECM, COL, FN, or LN [188]. Proliferating cell nuclear antigen (PCNA) was used as a measure to determine the proliferation response of CPCs cultured for 30 hours on the different substrates. The highest number of PCNA positive cells was observed on substrates functionalized with fibronectin, demonstrating the benefit of a single ECM component compared to the whole complex cardiac ECM. Fibronectin has been shown to be crucial for the expansion of human CPCs during development and after a MI [189]. Additionally, endogenous fibronectin production by human CPCs has been observed after 7 days in static culture [15]. Interestingly, the beneficial effect of fibronectin on the proliferation of CPCs seems to diminish at strain magnitudes of $10-15 \%$. These findings suggest the importance of fibronectin on the initial proliferation response of CPCs; however, the effect can be overruled by other microenvironmental components such as cyclic strain and/or stiffness.

(2) ECM Stiffness. The data described so far suggest that an ideal biochemical environment is not sufficient to completely obtain the desired regenerative response, but that mechanical and/or structural stimuli also contribute to a favorable response. To illustrate this, $\mathrm{c}^{-\mathrm{kit}^{+}}$human pediatric CPCs were cultured in neonatal or adult ECM derived from Sprague-Dawley rats and combined with fibrin to create 3D hybrid hydrogels with a range of Young's moduli, that is, 2, 8,14 , and $32 \mathrm{kPa}$ [190]. By increasing Young's modulus of the neonatal and adult ECM-fibrin hybrid hydrogel from 2 to $8 \mathrm{kPa}$, the gene expression of cardiac titin decreased, whereas it increased at higher moduli. These findings suggest that ECM stiffness has an effect on the genetic behavior of $\mathrm{CPCs}$ in terms of cardiac titin expression. Encapsulating CPCs in an environment with a stiffness that resembles the native mechanical properties would provide better conditions to study the development of CPCs into mature cardiomyocytes. However, this is complicated by the fact that stiffness values may differ between neonatal, fetal, and adult heart, between healthy and diseased conditions, and also between species [191].

To study the effect of ECM stiffness on cardiac stem/progenitor cell maturation, hydrogels with time-dependent and development-mimicking stiffnesses were developed based on thiolated-hyaluronic acid (HA) and crosslinked with poly(ethylene glycol) (PEG) diacrylate. By growing precardiac embryonic stem cells on HA-hydrogels with elastic moduli ranging from 1 to $10 \mathrm{kPa}$, a $60 \%$ increase in myofibril orientation and a 3-fold increase in Troponin $\mathrm{T}$ expression was observed compared to cells grown on mechanically static polyacrylamide hydrogels [192]. A recent example of modulating the ECM stiffness is shown by Choi et al., where a sol-to-gel transitional gelatin-PEG-tyramine (GPT) hydrogel with tunable mechanical properties was developed [193]. Hydrogels with elastic moduli of $1.8,2.8,5.8$, and $8.1 \mathrm{kPa}$ were created by varying the $\mathrm{H}_{2} \mathrm{O}_{2}$ concentration. Interestingly, CPCs isolated from 9-week-old Sprague-Dawley rats showed inhibited f-Actin organization and decreased proliferation in stiffer GPT hydrogels (elastic moduli of 5.8 and $8.1 \mathrm{kPa}$ ) compared to lower stiffnesses (1.8 and $2.8 \mathrm{kPa}$ ) [197]. However, an enhanced expression level of early cardiac differentiation markers was observed in GPT hydrogels with higher elastic moduli. These results strongly suggest an inhibition of proliferation and enhancement and differentiation in cardiac stem/ progenitor cells as a result of increasing the ECM stiffness.

3.3. Cyclic Strain. The adult human heart beats $60-100$ times per minute every day. Cells that reside in the myocardium are constantly subjected to this mechanical loading, which thus represents a significant component of the cardiac microenvironment that can influence the regenerative response of resident CPCs. However, while many studies have focused on the mechanoresponse of contractile cardiomyocytes, the effect of cyclic strain on CPCs has only been investigated by a few research groups. We recently elucidated the mechanoresponse of human Sca- $1^{+}$CPCs. Cells were cultured on 2D substrates coated with collagen IV, which together with laminin represents the main component of the cardiomyocyte basement membrane. Whereas undifferentiated CPCs did not show a preferential orientation upon application of uniaxial cyclic strain, CPCs in the early stage of cardiomyogenic differentiation (predifferentiated) oriented perpendicularly to the main direction of the stretch (strain avoidance behavior) after 48 hours [184]. The different responses appear to be 
due to the development of the mechanosensing structures, such as focal adhesions (FAs) and actin stress fibers (the mechanosome), that we demonstrated to occur during the early phase of cardiac differentiation [184]. In the study of French et al. [188] mentioned above, cyclically strained rat

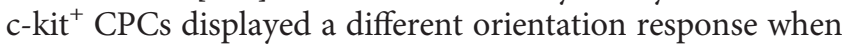
cultured on different ECM coatings. After 24 hours, rat CPCs displayed a strong strain avoidance response on fibronectin and collagen I. On the other hand, the strain avoidance response on cECM was much weaker as compared to collagen I and fibronectin, whereas almost no strain avoidance was observed on laminin [188]. Taken together, the reported studies suggest that CPCs on the natural cardiac ECM are less responsive to cyclic strain as compared to single ECM components (fibronectin, collagen I). Furthermore, the mechanoresponse of CPCs is weakened on certain ECM proteins (laminin, collagen IV). It is tempting to speculate that this behavior might be related to the affinity of different integrins for the ECM proteins. It would be interesting to investigate which integrins are expressed by the CPCs on the different substrates, and especially on the naturally derived cardiac ECM, and relate this expression pattern to the CPC mechanoresponse (as previously done in other cell types by $[194,195])$.

It should be noted that the above studies are limited by their $2 \mathrm{D}$ setup, which does not resemble the $3 \mathrm{D}$ physiologic environment. In a study by van Marion et al. [196], the effects of human Sca- $1^{+}$CPC engraftment in collagen I/Matrigel hydrogels were investigated. Whereas CPCs showed a random orientation in stress-free hydrogels, in statically constrained hydrogels, they aligned along the direction of the strain after 24 hours. This effect was even more pronounced at day 9 of culture, showing that CPCs become readily mechanosensitive in $3 \mathrm{D}$. Furthermore, already after 24 hours of culturing in the 3D hydrogels, the cardiac differentiation markers were upregulated as compared to the $2 \mathrm{D}$ culture, indicating an increased differentiation capacity of the CPCs towards the cardiomyocyte phenotype in 3D.

Detailed investigation of the mechanosensing of (human) CPCs in 3D environments is needed in order to provide a closer clue of the response of these cells to the mechanical stimuli provided by the cardiac microenvironment.

3.4. Soluble Factors and Oxygen Tension. After a myocardial infarction, cardiac cells are immediately exposed to hypoxia, due to the temporary lack of oxygen. Hypoxia has been shown to regulate the behavior of several stem and progenitor cells by dramatically influencing fundamental signaling pathways, such as Notch and Oct4, that determine selfrenewal and multipotency [197-199]. In response to low oxygen tension, cells express hypoxia-inducible factors (HIFs), with HIF- $1 \alpha$ being the key mediator of the cellular adaptive response to hypoxia [200]. For example, HIF- $1 \alpha$ is induced in the ischemic myocardium after MI [201]. HIF-1 directly regulates the transcription of the chemokine stromal cell-derived factor 1 (SDF-1) [202] and its receptors CXCR4 [203], which play an important role in the mobilization of progenitor cells [204-206]. Moreover, the upregulation of SDF-1 in ischemic tissues is directly proportional to the reduction of oxygen tension [202]. The interaction between SDF-1 and CXCR4 plays a crucial role in the mobilization and migration of circulating progenitor cells in ischemic tissues [202, 207, 208].

For cardiac regeneration, the response of resident progenitor cells to low oxygen tension is of great interest, due to the potential contribution of these cells to the cardiac regenerative mechanisms [38]. In this respect, a number of studies on murine CPCs have been conducted.

These cells express the SDF-1 receptors CXCR4 and CXCR7 $[209,210]$. In room air conditions $\left(20 \% \mathrm{O}_{2}\right)$, CPCs show very limited expression of CXCR4; however, under (harsh) hypoxia $\left(0.1 \% \mathrm{O}_{2}\right)$, expression of both the CXCR4 receptor and the chemokine SDF-1 is greatly enhanced [209]. SDF-1 induces CPC migration in a time- and dosedependent manner $[209,210]$; this SDF-1-induced migration is however abolished by knockdown of CXCR4 or CXCR7 [210], demonstrating the crucial role of the SDF-1/CXCR4 and SDF-1/CXCR7 axis for CPC motility. Pretreatment of murine CPCs with hypoxia results in increased migration toward SDF-1 in vitro, suppressed by cell transfection with CXCR4 shRNA [209], once again indicating the key role of the SDF-1/CXCR4 interaction for CPC motility. Additionally, hypoxic pretreatment results in improved recruitment of the CPCs to the ischemic myocardium in a mouse MI model [209], suggesting a potential therapeutic benefit was offered by this procedure.

The response to hypoxia of human CPCs is less known. In a study by van Oorschot et al. [211], human Scal ${ }^{+}$CPCs displayed increased proliferation and motility when cultured under low oxygen tension $\left(1 \% \mathrm{O}_{2}\right)$. The motility and migration of these cells were also enhanced by culture in $1 \% \mathrm{O}_{2}$ conditioned media [211]. Moreover, human $\mathrm{Scal}^{+} \mathrm{CPCs}$ displayed an increase in cell motility directly proportional to the reduction of oxygen tension, similarly to the SDF-1 induction observed in ischemic tissues by Ceradini and Gurtner [212]. In a hypoxia-gradient microfluidics chip, where high $\mathrm{O}_{2}$ tension was applied on one end $(20 \%$ or $95 \%)$ and $1 \% \mathrm{O}_{2}$ at the other end, an increasing number of human Sca ${ }^{+}$CPCs was detected after 24 hours towards the condition of the lowest oxygen tension (Figure 4). CPC displayed similar proliferation in all the areas of the chip, thereby suggesting that the higher amount of cells in the hypoxic area is indeed due to CPC migration.

This suggests that, under hypoxic conditions, not only do human CPCs show improved motility but they also release chemoattractants and their receptors. However, the induction of SDF1 and CXCR4/CXCR7 in human CPCs has not been investigated yet. Given the data here reported on murine CPCs and on other human progenitor cells, a mechanism similar to the SDF-1/CXCR4 axis might take place.

\section{Approaches to Modulate the CPC Microenvironment}

The CPC niche is complex and its importance for cardiac differentiation, maturation, and contribution to repair is largely unknown. For a better understanding, engineering approaches to recapitulate the native cardiac 


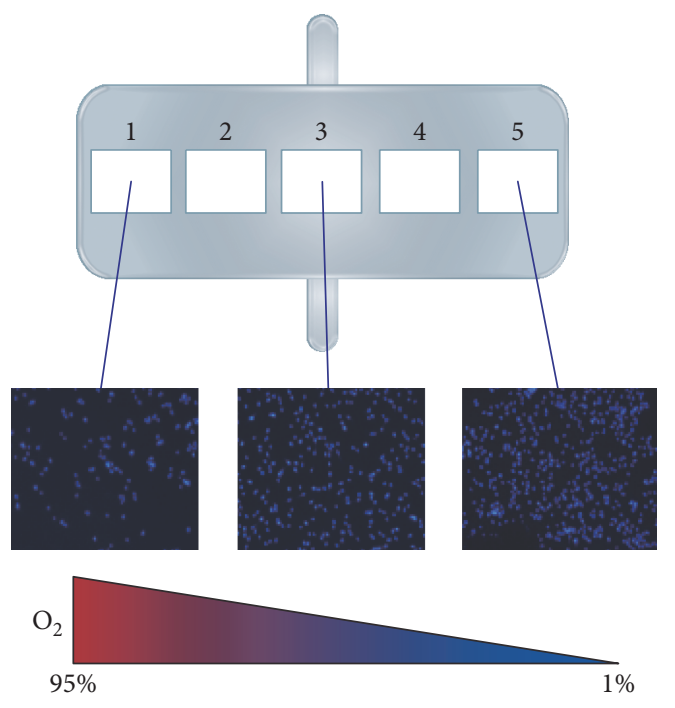

(a) Oxygen gradient device

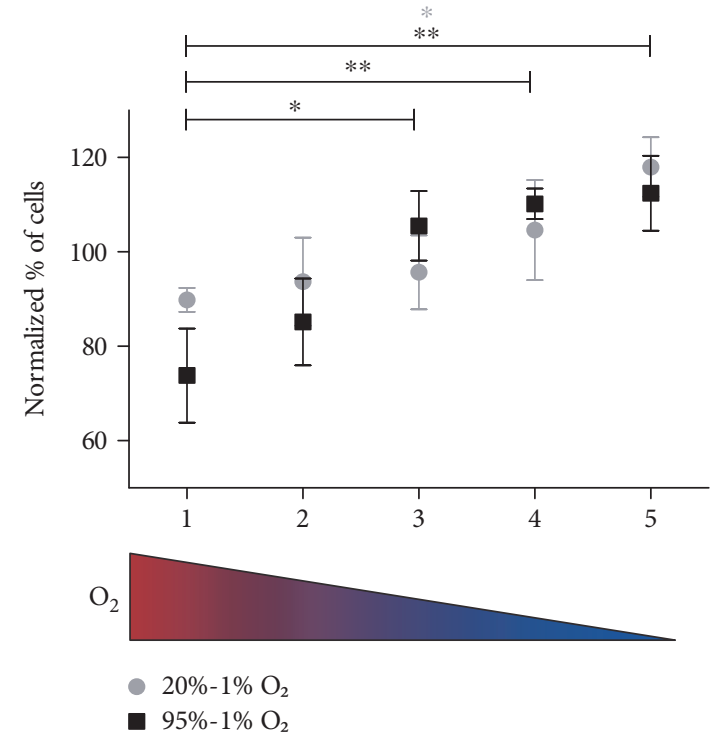

(b) Local cell amount

FIgURE 4: CPCs migrate toward lower oxygen concentration in an oxygen gradient device. (a) In a PDMS device (showed in the schematic representation) where $20 \%$ or $95 \% \mathrm{O}_{2}$ was applied at one end, and $1 \% \mathrm{O}_{2}$ at the other end, an increasing number of CPCs were observed at the lower oxygen side after 24 hours. Representative images show the increased amount of cells (nuclei stained with Hoechst 33342 , blue). (b) The quantification of cell number (normalized to the initial value after seeding) is reported as mean $\pm \operatorname{SD}\left(n=4\right.$; ${ }^{*} P<0.05$; $\left.{ }^{* *} P<0.01\right)$.

microenvironment are required. For recreating the $\mathrm{CPC}$ niche in vitro, several key components are of importance. In this part of the review, we will focus on current in vitro engineering approaches to mimic the cell natural environment (Figure 5).

As previously stated, the CPC microenvironment or niche should display key characteristics, such as optimal biochemical, physical, and mechanical properties, to enhance the regenerative response of CPCs. This ideal microenvironment should therefore stimulate either proliferation or differentiation, or elicit a beneficial effect on the paracrine signaling of CPCs. To date, little is known of the exact characteristics of this ideal niche and what is necessary to obtain optimal CPC contribution to cardiac regeneration.

Multicellular spheroids are scaffold-free spherical cell aggregates that mimic in the most simplistic way the conditions of the niche $[99,100,213]$. As compared to 2D cell culture, spheroids provide improved cell-cell and cell-ECM interactions, as well as gradients of soluble factors, such as oxygen and nutrients [213-216]. Therefore, cell spheroids are used as a model to study cell behavior in a $3 \mathrm{D}$ environment that better resembles the in vivo conditions. At the same time, they could entail major advantages for clinical use over the injection of cells grown as a monolayer, especially in the treatment of cardiac disease (as extensively described by $[169,216])$.

However, an engineered microenvironment could provide more specific signals to CPCs, and its characteristics might be tunable to elicit a distinct response. Currently hydrogels, decellularized ECM, and synthetic matrices are used to create $3 \mathrm{D}$ cardiac environments that take into account cell-matrix interactions, as described above.
However, though these matrices mimic ECM-like features, they not always resemble the mechanical strength of the native tissue [217]. Unfortunately, only a small amount of studies are performed with CPCs in matrices to create an engineered CPC-niche, although recently these are being increasingly explored [97, 188, 196, 218, 219]. Other cell types, which do not match the definition of CPCs of this review, are more prominently used in hydrogels, and the knowledge gained from these studies might be interesting to engineer the CPC niche. Cardiosphere-derived cells in both alginate [220] or biodegradable poly-( $\mathrm{N}$-isopropylacrylamide) hydrogels showed cardiomyogenic differentiation and proliferation [221] and provided functional benefits [222].

However, these approaches lack to take into account some key aspects of the cardiac microenvironment. By making more use of biomaterials that can form welldefined and "smart" microenvironments, more knowledge can be extracted to finally be able to define the ideal CPC niche. Recently, scalable engineered and force-generating human myocardium was produced under well-defined conditions using embryonic stem cells, induced pluripotent stem cell-derived cardiomyocytes, and fibroblasts [223]. Interestingly, extensive evidence for cardiac molecular maturation and functional tissue formation was obtained using RNA sequencing techniques. According to Tiburcy et al., the most important responses that determine the degree of in vitro maturation of human cardiomyocytes are artificial electrical pacing [224], mechanical stimulation (uniaxial and cyclic load) [225], and cocultures with fibroblast-like cells [226]. Finally, they were able to develop a model that can be used to screen drugs, study heart repair or model heart 


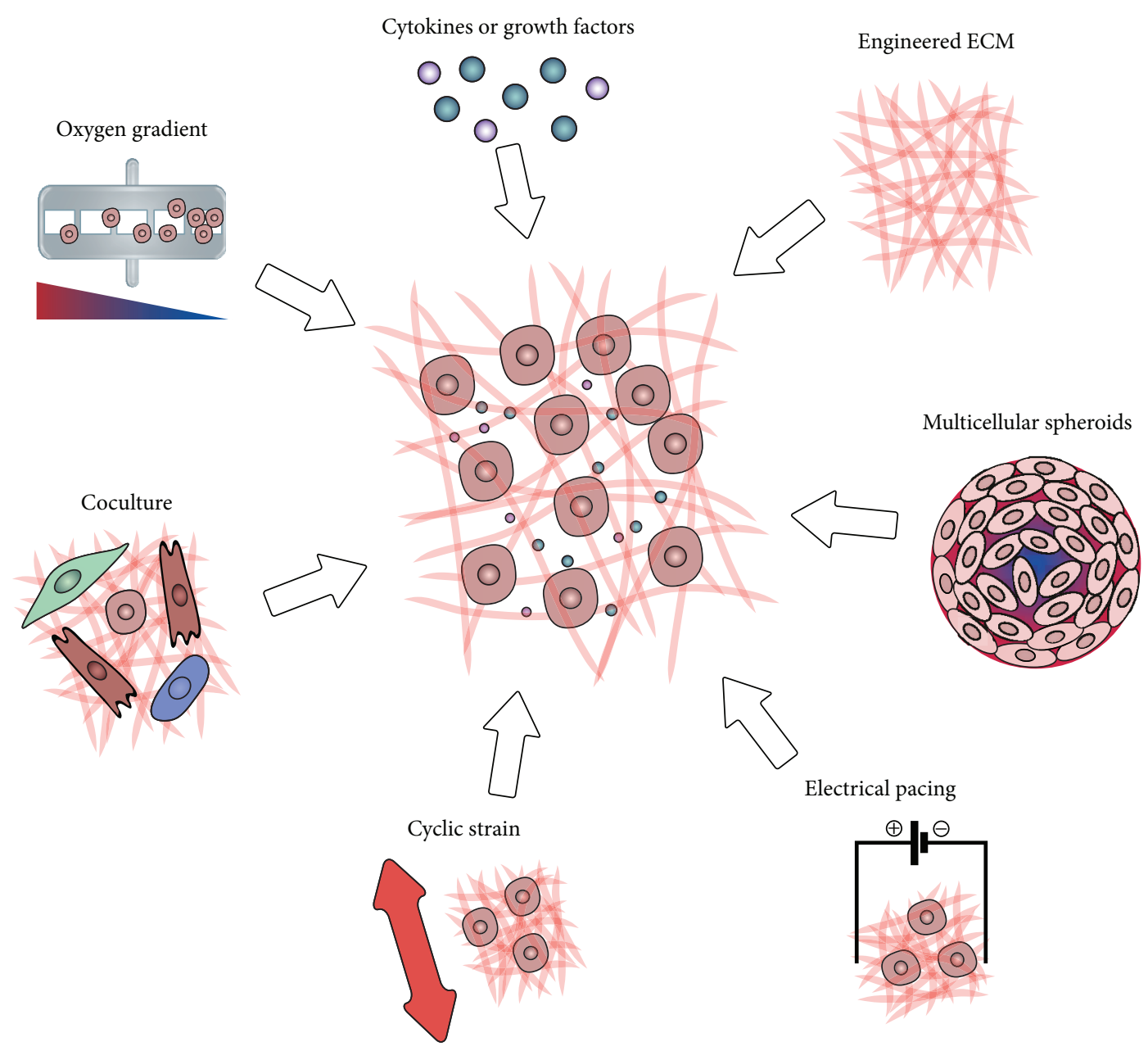

Figure 5: In vitro approaches to modulate the CPC niche. Strategies to optimize the regenerative potential of CPCs by modulating their microenvironment include (clockwise) the following: engineering the ECM with synthetic or naturally derived polymers with the right composition and physical properties; recreating a niche-like environment by growing cells as multicellular spheroids; applying electrical pacing and/or cyclic strain; co- and multiculture of different cell types to optimize cell-cell interactions, with or without surrounding ECM; and modulating the cell recruiting potential held by gradients of oxygen and cytokines and growth factors.

disease, and to study the endogenous repair of CPCs. Another method to create well-defined microenvironments is by making use of micro- and nanoscale engineered biological systems on a chip [227]. With these techniques, different niche components, such as mechanical [228-230], electrical [231], or topographical cues [232], can be carefully modulated and stem cell responses can then be studied in more detail. For instance, Morez et al. have shown improved cardiomyocyte differentiation from CPCs using silicone parallel microgrooves (10 $\mu \mathrm{m}$ wide and $3 \mu \mathrm{m}$ deep) in vitro [233].

Further in vitro research is needed on the influence of different niche components on the behavior and regenerative potential of CPCs, in order to make the final next step towards the successful endogenous cardiac repair by CPCs.

\section{Conclusive Remark}

In this review, we have defined cardiac resident progenitor cells according to their behavior and characteristics. Although there is ongoing debate and controversy about the presence of CPCs in the heart and their regenerative potential, a considerable amount of evidence shows that these cells exist and reside in the fetal and adult (human) heart in specific niches. We have highlighted the key components of CPC niches and the interplay of CPCs with niche elements.

As reported, the CPC niche is very complex in structure and composition and the relative and combined effects of individual niche elements on CPC function and regenerative potential is, to date, far from clear. Better understanding of the effect of the niche on cell behavior could lead to strategies to optimize their contribution to cardiac repair. Therefore, we concluded this review by describing how engineering in vitro approaches, that take into account the key factors and attempt to mimic the native niche, can enhance the regenerative response of CPCs.

\section{Conflicts of Interest}

The authors declare that they have no conflicts of interest. 


\section{Authors' Contributions}

Arianna Mauretti, Sergio Spaans, and Noortje A. M. Bax contributed equally to this work.

\section{Acknowledgments}

This research was funded by the People Program (Marie Curie Actions) of the European Union's Seventh Framework Program FP7-People-2012-ITN “TECAS” under Grant Agreement no. 317512 and FP7-People-2013-CIG under Grant Agreement no. 618623 and a grant of the Dutch Heart Foundation (DHF-2014T013).

\section{References}

[1] C. M. Ripplinger, S. F. Noujaim, and D. Linz, "The nervous heart," Progress in Biophysics and Molecular Biology, vol. 120, no. 1-3, pp. 199-209, 2016.

[2] M. Ieda, "Heart development, diseases, and regeneration new approaches from innervation, fibroblasts, and reprogramming," Circulation Journal, vol. 80, no. 10, pp. 20812088, 2016.

[3] N. Smart, "Prospects for improving neovascularization of the ischemic heart: lessons from development," Microcirculation, vol. 24, no. 1, 2017.

[4] E. Graham and O. Bergmann, "Dating the heart: exploring cardiomyocyte renewal in humans," Physiology (Bethesda, Maryland), vol. 32, no. 1, pp. 33-41, 2017.

[5] O. Bergmann, S. Zdunek, A. Felker et al., "Dynamics of cell generation and turnover in the human heart," Cell, vol. 161, no. 7, pp. 1566-1575, 2015.

[6] K. Urbanek, D. Torella, F. Sheikh et al., "Myocardial regeneration by activation of multipotent cardiac stem cells in ischemic heart failure," Proceedings of the National Academy of Sciences of the United States of America, vol. 102, no. 24, pp. 8692-8697, 2005.

[7] J. Bloomekatz, M. Galvez-Santisteban, and N. C. Chi, "Myocardial plasticity: cardiac development, regeneration and disease," Current Opinion in Genetics \& Development, vol. 40, pp. 120-130, 2016.

[8] J. H. van Berlo and J. D. Molkentin, "An emerging consensus on cardiac regeneration,” Nature Medicine, vol. 20, no. 12, pp. 1386-1393, 2014.

[9] S. X. Liang and W. D. Phillips, "Migration of resident cardiac stem cells in myocardial infarction," The Anatomical Record, vol. 296, no. 2, pp. 184-191, 2013.

[10] H. Oh, S. B. Bradfute, T. D. Gallardo et al., "Cardiac progenitor cells from adult myocardium: homing, differentiation, and fusion after infarction," Proceedings of the National Academy of Sciences of the United States of America, vol. 100, no. 21, pp. 12313-12318, 2003.

[11] T. Y. L. Le and J. J. H. Chong, "Cardiac progenitor cells for heart repair,” Cell Death Discovery, vol. 2, article 16052, 2016.

[12] K. Urbanek, F. Quaini, G. Tasca et al., "Intense myocyte formation from cardiac stem cells in human cardiac hypertrophy," Proceedings of the National Academy of Sciences of the United States of America, vol. 100, no. 18, pp. 10440-10445, 2003.

[13] K. Matsuura, T. Nagai, N. Nishigaki et al., "Adult cardiac Sca1-positive cells differentiate into beating cardiomyocytes,"
The Journal of Biological Chemistry, vol. 279, no. 12, pp. 11384-11391, 2004.

[14] O. Pfister, F. Mouquet, M. Jain et al., "CD31- but not CD31+ cardiac side population cells exhibit functional cardiomyogenic differentiation," Circulation Research, vol. 97, no. 1, pp. 52-61, 2005.

[15] N. A. M. Bax, M. H. van Marion, B. Shah, M.-J. Goumans, C. V. C. Bouten, and D. W. J. van der Schaft, "Matrix production and remodeling capacity of cardiomyocyte progenitor cells during in vitro differentiation," Journal of Molecular and Cellular Cardiology, vol. 53, no. 4, pp. 497-508, 2012.

[16] A. J. Boyle, S. P. Schulman, J. M. Hare, and P. Oettgen, "Is stem cell therapy ready for patients? Stem cell therapy for cardiac repair. Ready for the next step," Circulation, vol. 114, no. 4, pp. 339-352, 2006.

[17] P. P. Zwetsloot, A. M. D. Végh, S. J. Jansen of Lorkeers et al., "Cardiac stem cell treatment in myocardial infarction: a systematic review and meta-analysis of preclinical studies," Circulation Research, vol. 118, no. 8, pp. 1223-1232, 2016.

[18] P. Menasche, "Cardiac cell therapy: lessons from clinical trials," Journal of Molecular and Cellular Cardiology, vol. 50, no. 2, pp. 258-265, 2011.

[19] K. Malliaras and E. Marban, "Cardiac cell therapy: where we've been, where we are, and where we should be headed," British Medical Bulletin, vol. 98, pp. 161-185, 2011.

[20] D. Vanhoutte, M. Schellings, Y. Pinto, and S. Heymans, "Relevance of matrix metalloproteinases and their inhibitors after myocardial infarction: a temporal and spatial window," Cardiovascular Research, vol. 69, no. 3, pp. 604-613, 2006.

[21] J. C. Deddens, A. H. Sadeghi, J. Hjortnaes et al., "Modeling the human scarred heart in vitro: toward new tissue engineered models," Advanced Healthcare Materials, vol. 6, no. 3, 2017.

[22] M. Dobaczewski, C. Gonzalez-Quesada, and N. G. Frangogiannis, "The extracellular matrix as a modulator of the inflammatory and reparative response following myocardial infarction," Journal of Molecular and Cellular Cardiology, vol. 48, no. 3, pp. 504-511, 2010.

[23] D. L. Jones and A. J. Wagers, "No place like home: anatomy and function of the stem cell niche," Nature Reviews Molecular Cell Biology, vol. 9, no. 1, pp. 11-21, 2008.

[24] K. A. Moore and I. R. Lemischka, "Stem cells and their niches," Science, vol. 311, no. 5769, pp. 1880-1885, 2006.

[25] R. Schofield, "The relationship between the spleen colonyforming cell and the haemopoietic stem cell," Blood Cells, vol. 4, no. 1-2, pp. 7-25, 1978.

[26] S. J. Morrison and A. C. Spradling, "Stem cells and niches: mechanisms that promote stem cell maintenance throughout life," Cell, vol. 132, no. 4, pp. 598-611, 2008.

[27] K. Urbanek, D. Cesselli, M. Rota et al., "Stem cell niches in the adult mouse heart," Proceedings of the National Academy of Sciences of the United States of America, vol. 103, no. 24, pp. 9226-9231, 2006.

[28] A. Leri, M. Rota, T. Hosoda, P. Goichberg, and P. Anversa, "Cardiac stem cell niches," Stem Cell Research, vol. 13, no. 3, Part B, pp. 631-646, 2014.

[29] C. M. Martin, A. P. Meeson, S. M. Robertson et al., "Persistent expression of the ATP-binding cassette transporter, Abcg2, identifies cardiac SP cells in the developing and adult heart," Developmental Biology, vol. 265, no. 1, pp. 262-275, 2004. 
[30] K. Wei, V. Serpooshan, C. Hurtado et al., "Epicardial FSTL1 reconstitution regenerates the adult mammalian heart," Nature, vol. 525, no. 7570, pp. 479-485, 2015.

[31] S. X. Liang, T. Y. L. Tan, L. Gaudry, and B. Chong, "Differentiation and migration of Sca1+/CD31- cardiac side population cells in a murine myocardial ischemic model," International Journal of Cardiology, vol. 138, no. 1, pp. 40-49, 2010.

[32] A. M. Hierlihy, P. Seale, C. G. Lobe, M. A. Rudnicki, and L. A. Megeney, "The post-natal heart contains a myocardial stem cell population," FEBS Letters, vol. 530, no. 1-3, pp. 239-243, 2002.

[33] T. Oyama, T. Nagai, H. Wada et al., "Cardiac side population cells have a potential to migrate and differentiate into cardiomyocytes in vitro and in vivo," The Journal of Cell Biology, vol. 176, no. 3, pp. 329-341, 2007.

[34] M. Alfakir, N. Dawe, R. Eyre et al., "The temporal and spatial expression patterns of ABCG2 in the developing human heart," International Journal of Cardiology, vol. 156, no. 2, pp. 133-138, 2012.

[35] J. Sandstedt, M. Jonsson, K. Vukusic et al., "SSEA-4+ CD34cells in the adult human heart show the molecular characteristics of a novel cardiomyocyte progenitor population," Cells, Tissues, Organs, vol. 199, no. 2-3, pp. 103-116, 2014.

[36] S. X. Liang, L. M. Khachigian, Z. Ahmadi, M. Yang, S. Liu, and B. H. Chong, "In vitro and in vivo proliferation, differentiation and migration of cardiac endothelial progenitor cells (SCA1+/CD31+ side-population cells)," Journal of Thrombosis and Haemostasis, vol. 9, no. 8, pp. 1628-1637, 2011.

[37] K. Yamahara, S. Fukushima, S. R. Coppen et al., "Heterogeneic nature of adult cardiac side population cells," Biochemical and Biophysical Research Communications, vol. 371, no. 4, pp. 615-620, 2008.

[38] M. Y. Emmert, L. S. Emmert, A. Martens et al., "Higher frequencies of BCRP+ cardiac resident cells in ischaemic human myocardium," European Heart Journal, vol. 34, no. 36, pp. 2830-2838, 2013.

[39] E. B. Lushaj, L. Lozonschi, M. Barnes, E. Anstadt, and T. Kohmoto, "Mitochondrial DNA deletion mutations in adult mouse cardiac side population cells," Mutation Research, vol. 734, no. 1-2, pp. 62-68, 2012.

[40] E. Belian, M. Noseda, M. S. Abreu Paiva, T. Leja, R. Sampson, and M. D. Schneider, "Forward programming of cardiac stem cells by homogeneous transduction with MYOCD plus TBX5," PLoS One, vol. 10, no. 6, article e0125384, 2015.

[41] J. Yoon, S. C. Choi, C. Y. Park, W. J. Shim, and D.-S. Lim, "Cardiac side population cells exhibit endothelial differentiation potential," Experimental \& Molecular Medicine, vol. 39, no. 5, pp. 653-662, 2007.

[42] F. Mouquet, O. Pfister, M. Jain et al., "Restoration of cardiac progenitor cells after myocardial infarction by self-proliferation and selective homing of bone marrowderived stem cells," Circulation Research, vol. 97, no. 11, pp. 1090-1092, 2005.

[43] C. M. Martin, A. Ferdous, T. Gallardo et al., "Hypoxiainducible factor-2alpha transactivates $\mathrm{Abcg} 2$ and promotes cytoprotection in cardiac side population cells," Circulation Research, vol. 102, no. 9, pp. 1075-1081, 2008.

[44] K. Meissner, B. Heydrich, G. Jedlitschky et al., "The ATPbinding cassette transporter ABCG2 (BCRP), a marker for side population stem cells, is expressed in human heart,"
The Journal of Histochemistry and Cytochemistry, vol. 54, no. 2, pp. 215-221, 2006.

[45] A. P. Beltrami, L. Barlucchi, D. Torella et al., "Adult cardiac stem cells are multipotent and support myocardial regeneration," Cell, vol. 114, no. 6, pp. 763-776, 2003.

[46] G. M. Ellison, V. Galuppo, C. Vicinanza et al., "Cardiac stem and progenitor cell identification: different markers for the same cell?," Fronteirs in Bioscience (Scholar Edition), vol. 2, pp. 641-652, 2010.

[47] C. Bearzi, M. Rota, T. Hosoda et al., "Human cardiac stem cells," Proceedings of the National Academy of Sciences of the United States of America, vol. 104, no. 35, pp. 1406814073, 2007.

[48] N. Sultana, L. Zhang, J. Yan et al., "Resident c-kit(+) cells in the heart are not cardiac stem cells," Nature Communications, vol. 6, p. 8701, 2015.

[49] M. M. Zaruba, M. Soonpaa, S. Reuter, and L. J. Field, "Cardiomyogenic potential of C-kit(+)-expressing cells derived from neonatal and adult mouse hearts," Circulation, vol. 121, no. 18, pp. 1992-2000, 2010.

[50] M. Hesse, B. K. Fleischmann, and M. I. Kotlikoff, "Concise review: the role of $\mathrm{C}$-kit expressing cells in heart repair at the neonatal and adult stage," Stem Cells, vol. 32, no. 7, pp. 1701-1712, 2014.

[51] C. Castaldo, F. Di Meglio, D. Nurzynska et al., "CD117positive cells in adult human heart are localized in the subepicardium, and their activation is associated with laminin-1 and alpha6 integrin expression," Stem Cells, vol. 26, pp. 1723-1731, 2008.

[52] S. Matuszczak, J. Czapla, M. Jarosz-Biej et al., "Characteristic of c-kit+ progenitor cells in explanted human hearts," Clinical Research in Cardiology, vol. 103, no. 9, pp. 711718, 2014.

[53] Y. N. Tallini, K. S. Greene, M. Craven et al., "C-kit expression identifies cardiovascular precursors in the neonatal heart," Proceedings of the National Academy of Sciences of the United States of America, vol. 106, no. 6, pp. 1808-1813, 2009.

[54] M. Saravanakumar and H. Devaraj, "Distribution and homing pattern of c-kit+ Sca-1+ CXCR4+ resident cardiac stem cells in neonatal, postnatal, and adult mouse heart," Cardiovascular Pathology, vol. 22, no. 4, pp. 257-263, 2013.

[55] A. Linke, P. Muller, D. Nurzynska et al., "Stem cells in the dog heart are self-renewing, clonogenic, and multipotent and regenerate infarcted myocardium, improving cardiac function," Proceedings of the National Academy of Sciences of the United States of America, vol. 102, no. 25, pp. 8966-8971, 2005.

[56] G. M. Ellison, D. Torella, S. Dellegrottaglie et al., "Endogenous cardiac stem cell activation by insulin-like growth factor-1/hepatocyte growth factor intracoronary injection fosters survival and regeneration of the infarcted pig heart," Journal of the American College of Cardiology, vol. 58, no. 9, pp. 977-986, 2011.

[57] X. Hou, N. Appleby, T. Fuentes et al., "Isolation, characterization, and spatial distribution of cardiac progenitor cells in the sheep heart," Journal of Clinical \& Experimental Cardiology, vol. S6, 2012.

[58] D. Dey, L. Han, M. Bauer et al., "Dissecting the molecular relationship among various cardiogenic progenitor cells," Circulation Research, vol. 112, no. 9, pp. 12531262, 2013. 
[59] P. Anversa, J. Kajstura, A. Leri, and R. Bolli, "Life and death of cardiac stem cells: a paradigm shift in cardiac biology," Circulation, vol. 113, no. 11, pp. 1451-1463, 2006.

[60] M. P. Santini, E. Forte, R. P. Harvey, and J. C. Kovacic, "Developmental origin and lineage plasticity of endogenous cardiac stem cells," Development, vol. 143, pp. 1242-1258, 2016.

[61] S. A. Jesty, M. A. Steffey, F. K. Lee et al., "C-kit+ precursors support postinfarction myogenesis in the neonatal, but not adult, heart," Proceedings of the National Academy of Sciences of the United States of America, vol. 109, no. 33, pp. 1338013385, 2012.

[62] D. L. Simpson, R. Mishra, S. Sharma, S. K. Goh, S. Deshmukh, and S. Kaushal, "A strong regenerative ability of cardiac stem cells derived from neonatal hearts," Circulation, vol. 126, no. 11, Supplement 1, pp. S46-S53, 2012.

[63] F. Limana, A. Zacheo, D. Mocini et al., "Identification of myocardial and vascular precursor cells in human and mouse epicardium," Circulation Research, vol. 101, no. 12, pp. 12551265, 2007.

[64] C. Di Filippo, M. Luongo, R. Marfella et al., "Oxygen/ozone protects the heart from acute myocardial infarction through local increase of eNOS activity and endothelial progenitor cells recruitment," Naunyn-Schmiedeberg's Archives of Pharmacology, vol. 382, no. 3, pp. 287-291, 2010.

[65] C. Di Filippo, M. Perretti, F. Rossi, F. Ferraraccio, R. Motterlini, and M. D'Amico, "Acute myocardial infarction in streptozotocin-induced hyperglycaemic rats: protection by a carbon monoxide-releasing molecule (CORM-3)," Naunyn-Schmiedeberg's Archives of Pharmacology, vol. 385, no. 2, pp. 137-144, 2012.

[66] L. Zakharova, H. Nural-Guvener, J. Nimlos, S. Popovic, and M. A. Gaballa, "Chronic heart failure is associated with transforming growth factor beta-dependent yield and functional decline in atrial explant-derived c-kit+ cells," Journal of the American Heart Association, vol. 2, no. 5, article e000317, 2013.

[67] A. Itzhaki-Alfia, J. Leor, E. Raanani et al., "Patient characteristics and cell source determine the number of isolated human cardiac progenitor cells," Circulation, vol. 120, no. 25, pp. 2559-2566, 2009.

[68] M. Rota, M. E. Padin-Iruegas, Y. Misao et al., "Local activation or implantation of cardiac progenitor cells rescues scarred infarcted myocardium improving cardiac function," Circulation Research, vol. 103, no. 1, pp. 107-116, 2008.

[69] X.-L. Tang, G. Rokosh, S. K. Sanganalmath et al., "Intracoronary administration of cardiac progenitor cells alleviates left ventricular dysfunction in rats with a 30-day-old infarction," Circulation, vol. 121, no. 2, pp. 293-305, 2010.

[70] R. Bolli, X.-L. Tang, S. K. Sanganalmath et al., "Intracoronary delivery of autologous cardiac stem cells improves cardiac function in a porcine model of chronic ischemic cardiomyopathy," Circulation, vol. 128, no. 2, pp. 122-131, 2013.

[71] R. Bolli, A. R. Chugh, D. D’Amario et al., "Cardiac stem cells in patients with ischaemic cardiomyopathy (SCIPIO): initial results of a randomised phase 1 trial," Lancet (London, England), vol. 378, no. 9806, pp. 1847-1857, 2011.

[72] A. R. Chugh, G. M. Beache, J. H. Loughran et al., “Administration of cardiac stem cells in patients with ischemic cardiomyopathy: the SCIPIO trial: surgical aspects and interim analysis of myocardial function and viability by magnetic resonance," Circulation, vol. 126, no. 11, Supplement 1, pp. S54-S64, 2012.

[73] P. van Vliet, M. Roccio, A. M. Smits et al., "Progenitor cells isolated from the human heart: a potential cell source for regenerative therapy," Netherlands Heart Journal, vol. 16, no. 5, pp. 163-169, 2008.

[74] X. Wang, Q. Hu, Y. Nakamura et al., "The role of the Sca-1 $+/ \mathrm{CD} 31$ - cardiac progenitor cell population in postinfarction left ventricular remodeling," Stem Cells, vol. 24, no. 7, pp. 1779-1788, 2006.

[75] M. J. Goumans, T. P. de Boer, A. M. Smits et al., “TGF- $\beta 1$ induces efficient differentiation of human cardiomyocyte progenitor cells into functional cardiomyocytes in vitro," Stem Cell Research, vol. 1, no. 2, pp. 138-149, 2008.

[76] A. M. Smits, P. van Vliet, C. H. Metz et al., "Human cardiomyocyte progenitor cells differentiate into functional mature cardiomyocytes: an in vitro model for studying human cardiac physiology and pathophysiology," Nature Protocols, vol. 4, no. 2, pp. 232-243, 2009.

[77] P. van Vliet, T. P. de Boer, M. A. G. van der Heyden et al., "Hyperpolarization induces differentiation in human cardiomyocyte progenitor cells," Stem Cell Reviews, vol. 6, no. 2, pp. 178-185, 2010.

[78] P. van Vliet, A. M. Smits, T. P. de Boer et al., "Foetal and adult cardiomyocyte progenitor cells have different developmental potential," Journal of Cellular and Molecular Medicine, vol. 14, no. 4, pp. 861-870, 2010.

[79] K. Matsuura, A. Honda, T. Nagai et al., "Transplantation of cardiac progenitor cells ameliorates cardiac dysfunction after myocardial infarction in mice," Journal of Clinical Investigation, vol. 119, no. 8, 2009.

[80] M. C. den Haan, R. W. Grauss, A. M. Smits et al., "Cardiomyogenic differentiation-independent improvement of cardiac function by human cardiomyocyte progenitor cell injection in ischaemic mouse hearts," Journal of Cellular and Molecular Medicine, vol. 16, no. 7, pp. 1508-1521, 2012.

[81] J. W. Holmes, T. K. Borg, and J. W. Covell, "Structure and mechanics of healing myocardial infarcts," Annual Review of Biomedical Engineering, vol. 7, pp. 223-253, 2005.

[82] H. W. Leung, A. T. Moerkamp, J. Padmanabhan, S.-W. Ng, M.-J. Goumans, and A. Choo, "mAb C19 targets a novel surface marker for the isolation of human cardiac progenitor cells from human heart tissue and differentiated hESCs," Journal of Molecular and Cellular Cardiology, vol. 82, pp. 228-237, 2015.

[83] L. Barile, M. Gherghiceanu, L. M. Popescu, T. Moccetti, and G. Vassalli, "Human cardiospheres as a source of multipotent stem and progenitor cells," Stem Cells International, vol. 2013, Article ID 916837, 10 pages, 2013.

[84] C. F. Leite, T. R. Almeida, C. S. Lopes, and V. J. Dias da Silva, "Multipotent stem cells of the heart-do they have therapeutic promise?," Frontiers in Physiology, vol. 6, p. 123, 2015.

[85] A. Moretti, L. Caron, A. Nakano et al., "Multipotent embryonic Isl1+ progenitor cells lead to cardiac, smooth muscle, and endothelial cell diversification," Cell, vol. 127, no. 6, pp. 1151-1165, 2006.

[86] P. Pandur, I. O. Sirbu, S. J. Kühl, M. Philipp, and M. Kühl, "Islet1-expressing cardiac progenitor cells: a comparison across species," Development Genes and Evolution, vol. 223, no. 1-2, pp. 117-129, 2013. 
[87] C. L. Cai, X. Liang, Y. Shi et al., "Isl1 identifies a cardiac progenitor population that proliferates prior to differentiation and contributes a majority of cells to the heart," Developmental Cell, vol. 5, no. 6, pp. 877-889, 2003.

[88] R. Genead, C. Danielsson, A. B. Andersson et al., "Islet-1 cells are cardiac progenitors present during the entire lifespan: from the embryonic stage to adulthood," Stem Cells and Development, vol. 19, no. 10, pp. 1601-1615, 2010.

[89] L. Bu, X. Jiang, S. Martin-Puig et al., "Human ISL1 heart progenitors generate diverse multipotent cardiovascular cell lineages," Nature, vol. 460, no. 7251, pp. 113-117, 2009.

[90] K.-L. Laugwitz, A. Moretti, J. Lam et al., "Postnatal isl1+ cardioblasts enter fully differentiated cardiomyocyte lineages," Nature, vol. 433, no. 7026, pp. 647-653, 2005.

[91] G. Amir, X. Ma, V. M. Reddy et al., "Dynamics of human myocardial progenitor cell populations in the neonatal period," The Annals of Thoracic Surgery, vol. 86, pp. 13111319, 2008.

[92] K. L. Laugwitz, A. Moretti, L. Caron, A. Nakano, and K. R. Chien, "Islet1 cardiovascular progenitors: a single source for heart lineages?," Development, vol. 135, no. 2, pp. 193-205, 2008.

[93] Y. Qyang, S. Martin-Puig, M. Chiravuri et al., “The renewal and differentiation of Isl1+ cardiovascular progenitors are controlled by a Wnt/beta-catenin pathway," Cell Stem Cell, vol. 1, no. 2, pp. 165-179, 2007.

[94] P. Khattar, F. W. Friedrich, G. Bonne et al., "Distinction between two populations of islet-1-positive cells in hearts of different murine strains," Stem Cells and Development, vol. 20, no. 6, pp. 1043-1052, 2011.

[95] R. Genead, H. Fischer, A. Hussain et al., "Ischemia-reperfusion injury and pregnancy initiate time-dependent and robust signs of up-regulation of cardiac progenitor cells," PloS One, vol. 7, no. 5, article e36804, 2012.

[96] E. Messina, L. De Angelis, G. Frati et al., "Isolation and expansion of adult cardiac stem cells from human and murine heart," Circulation Research, vol. 95, no. 9, pp. 911921, 2004.

[97] I. Chimenti, R. Gaetani, L. Barile et al., "Isolation and expansion of adult cardiac stem/progenitor cells in the form of cardiospheres from human cardiac biopsies and murine hearts," in Somatic Stem Cells: Methods and Protocols, S. R. Singh, Ed., pp. 327-338, Humana Press, Totowa, NJ, USA, 2012.

[98] R. R. Smith, L. Barile, H. C. Cho et al., "Regenerative potential of cardiosphere-derived cells expanded from percutaneous endomyocardial biopsy specimens," Circulation, vol. 115, no. 7, pp. 896-908, 2007.

[99] D. R. Davis, Y. Zhang, R. R. Smith et al., "Validation of the cardiosphere method to culture cardiac progenitor cells from myocardial tissue," PLoS One, vol. 4, no. 9, article e7195, 2009.

[100] T.-S. Li, K. Cheng, S.-T. Lee et al., "Cardiospheres recapitulate a niche-like microenvironment rich in stemness and cellmatrix interactions, rationalizing their enhanced functional potency for myocardial repair," Stem Cells, vol. 28, no. 11, pp. 2088-2098, 2010.

[101] P. V. Johnston, T. Sasano, K. Mills et al., "Engraftment, differentiation, and functional benefits of autologous cardiosphere-derived cells in porcine ischemic cardiomyopathy," Circulation, vol. 120, no. 12, pp. 1075-1083, 2009.
[102] S.-T. Lee, A. J. White, S. Matsushita et al., "Intramyocardial injection of autologous cardiospheres or cardiospherederived cells preserves function and minimizes adverse ventricular remodeling in pigs with heart failure postmyocardial infarction," Journal of the American College of Cardiology, vol. 57, no. 4, pp. 455-465, 2011.

[103] D. Shen, K. Cheng, and E. Marbán, "Dose-dependent functional benefit of human cardiosphere transplantation in mice with acute myocardial infarction," Journal of Cellular and Molecular Medicine, vol. 16, no. 9, pp. 2112-2116, 2012.

[104] K. Cheng, K. Malliaras, R. R. Smith et al., "Human cardiosphere-derived cells from advanced heart failure patients exhibit augmented functional potency in myocardial repair," JACC Heart Failure, vol. 2, no. 1, pp. 49-61, 2014.

[105] E. Tseliou, H. Reich, G. de Couto et al., "Cardiospheres reverse adverse remodeling in chronic rat myocardial infarction: roles of soluble endoglin and Tgf- $\beta$ signaling," Basic Research in Cardiology, vol. 109, no. 6, p. 443, 2014.

[106] K. Yee, K. Malliaras, H. Kanazawa et al., “Allogeneic cardiospheres delivered via percutaneous transendocardial injection increase viable myocardium, decrease scar size, and attenuate cardiac dilatation in porcine ischemic cardiomyopathy," PLoS One, vol. 9, no. 12, article e113805, 2014.

[107] J. Ye, A. Boyle, H. Shih et al., "Sca-1 $1^{+}$cardiosphere-derived cells are enriched for isl1-expressing cardiac precursors and improve cardiac function after myocardial injury," PLoS One, vol. 7, no. 1, article e30329, 2012.

[108] R. R. Makkar, R. R. Smith, K. Cheng et al., "Intracoronary cardiosphere-derived cells for heart regeneration after myocardial infarction (CADUCEUS): a prospective, randomised phase 1 trial," Lancet (London, England), vol. 379, no. 9819, pp. 895-904, 2012.

[109] K. Malliaras, R. R. Makkar, R. R. Smith et al., "Intracoronary cardiosphere-derived cells after myocardial infarction: evidence of therapeutic regeneration in the final 1-year results of the CADUCEUS trial (CArdiosphere-derived aUtologous stem CElls to reverse ventricular dysfunction)," Journal of the American College of Cardiology, vol. 63, no. 2, pp. 110-122, 2014.

[110] T. Chakravarty, R. R. Makkar, D. D. Ascheim et al., “ALLogeneic heart STem cells to achieve myocardial regeneration (ALLSTAR) trial: rationale and design," Cell Transplantation, vol. 26, no. 2, pp. 205-214, 2017.

[111] C. Bearzi, A. Leri, F. Lo Monaco et al., "Identification of a coronary vascular progenitor cell in the human heart," Proceedings of the National Academy of Sciences of the United States of America, vol. 106, no. 37, pp. 15885-15890, 2009.

[112] H. Kubo, N. Jaleel, A. Kumarapeli et al., "Increased cardiac myocyte progenitors in failing human hearts," Circulation, vol. 118, no. 6, pp. 649-657, 2008.

[113] K. C. Flanders, M. G. Holder, and T. S. Winokur, "Autoinduction of mRNA and protein expression for transforming growth factor-beta $\mathrm{S}$ in cultured cardiac cells," Journal of Molecular and Cellular Cardiology, vol. 27, no. 2, pp. 805812, 1995.

[114] A. Behfar, L. V. Zingman, D. M. Hodgson et al., "Stem cell differentiation requires a paracrine pathway in the heart," The FASEB Journal, vol. 16, no. 12, pp. 1558-1566, 2002.

[115] A. Deb, "Cell-cell interaction in the heart via Wnt/ $\beta$-catenin pathway after cardiac injury," Cardiovascular Research, vol. 102, no. 2, pp. 214-223, 2014. 
[116] T. Hosoda, H. Zheng, M. Cabral-Da-Silva et al., "Human cardiac stem cell differentiation is regulated by a mircrine mechanism," Circulation, vol. 123, no. 12, pp. 1287-1296, 2011.

[117] A. Gonzalez, M. Rota, D. Nurzynska et al., "Activation of cardiac progenitor cells reverses the failing heart senescent phenotype and prolongs lifespan," Circulation Research, vol. 102, no. 5, pp. 597-606, 2008.

[118] A. M. Samarel, "Costameres, focal adhesions, and cardiomyocyte mechanotransduction," American Journal of Physiology Heart and Circulatory Physiology, vol. 289, no. 6, pp. H2291-H2301, 2005.

[119] F. A. High, M. M. Lu, W. S. Pear, K. M. Loomes, K. H. Kaestner, and J. A. Epstein, "Endothelial expression of the Notch ligand Jagged 1 is required for vascular smooth muscle development," Proceedings of the National Academy of Sciences, vol. 105, no. 6, pp. 1955-1959, 2008.

[120] N. Gude, E. Joyo, H. Toko et al., "Notch activation enhances lineage commitment and protective signaling in cardiac progenitor cells," Basic Research in Cardiology, vol. 110, no. 3, p. 29, 2015.

[121] C. Urbich, A. Aicher, C. Heeschen et al., "Soluble factors released by endothelial progenitor cells promote migration of endothelial cells and cardiac resident progenitor cells," Journal of Molecular and Cellular Cardiology, vol. 39, no. 5, pp. 733-742, 2005.

[122] I. Zlatanova, C. Pinto, and J.-S. Silvestre, "Immune modulation of cardiac repair and regeneration: the art of mending broken hearts," Frontiers in Cardiovascular Medicine, vol. 3, p. 40, 2016.

[123] L. Raffaghello, G. Bianchi, M. Bertolotto et al., "Human mesenchymal stem cells inhibit neutrophil apoptosis: a model for neutrophil preservation in the bone marrow niche," Stem Cells, vol. 26, no. 1, pp. 151-162, 2008.

[124] S. Aggarwal and M. F. Pittenger, "Human mesenchymal stem cells modulate allogeneic immune cell responses," Blood, vol. 105, no. 4, pp. 1815-1822, 2005.

[125] M. Di Nicola, C. Carlo-Stella, M. Magni et al., "Human bone marrow stromal cells suppress T-lymphocyte proliferation induced by cellular or nonspecific mitogenic stimuli," Blood, vol. 99, no. 10, pp. 3838-3843, 2002.

[126] F. van den Akker, J. C. Deddens, P. A. Doevendans, and J. P. G. Sluijter, "Cardiac stem cell therapy to modulate inflammation upon myocardial infarction," Biochimica et Biophysica Acta (BBA) - General Subjects, vol. 1830, no. 2, pp. 24492458,2013

[127] K. Fujiu, J. Wang, and R. Nagai, "Cardioprotective function of cardiac macrophages," Cardiovascular Research, vol. 102, no. 2, pp. 232-239, 2014

[128] P. C. H. Hsieh, M. E. Davis, J. Gannon, C. MacGillivray, and R. T. Lee, "Controlled delivery of PDGF-BB for myocardial protection using injectable self-assembling peptide nanofibers," The Journal of Clinical Investigation, vol. 116, no. 1, pp. 237-248, 2006.

[129] K. M. Vannella and T. A. Wynn, "Mechanisms of organ injury and repair by macrophages," Annual Review of Physiology, vol. 79, no. 1, pp. 593-617, 2017.

[130] G. de Couto, W. Liu, E. Tseliou et al., "Macrophages mediate cardioprotective cellular postconditioning in acute myocardial infarction," The Journal of Clinical Investigation, vol. 125, no. 8, pp. 3147-3162, 2015.
[131] K. S. Campbell and J. Hasegawa, "Natural killer cell biology: an update and future directions," The Journal of Allergy and Clinical Immunology, vol. 132, no. 3, pp. 536-544, 2013.

[132] W. Boukouaci, L. Lauden, J. Siewiera et al., "Natural killer cell crosstalk with allogeneic human cardiac-derived stem/progenitor cells controls persistence," Cardiovascular Research, vol. 104, no. 2, pp. 290-302, 2014.

[133] Y. Zhou, P. Pan, L. Yao et al., "CD117-positive cells of the heart: progenitor cells or mast cells?," The Journal of Histochemistry and Cytochemistry, vol. 58, no. 4, pp. 309-316, 2010.

[134] N. Takeda and I. Manabe, "Cellular interplay between cardiomyocytes and nonmyocytes in cardiac remodeling," International Journal of Inflammation, vol. 2011, Article ID 535241, 13 pages, 2011

[135] P. Balakumar, A. P. Singh, S. S. Ganti, P. Krishan, S. Ramasamy, and M. Singh, "Resident cardiac mast cells: are they the major culprit in the pathogenesis of cardiac hypertrophy?," Basic \& Clinical Pharmacology \& Toxicology, vol. 102, no. 1, pp. 5-9, 2008.

[136] X. Zhang, M.-R. Shen, Z.-D. Xu et al., "Cardiomyocyte differentiation induced in cardiac progenitor cells by cardiac fibroblast-conditioned medium," Experimental Biology and Medicine (Maywood, N.J.), vol. 239, no. 5, pp. 628-637, 2014.

[137] T. Moore-Morris, N. Guimaraes-Camboa, I. Banerjee et al., "Resident fibroblast lineages mediate pressure overloadinduced cardiac fibrosis," The Journal of Clinical Investigation, vol. 124, no. 7, pp. 2921-2934, 2014.

[138] B. Zhou, L. B. Honor, H. He et al., "Adult mouse epicardium modulates myocardial injury by secreting paracrine factors," The Journal of Clinical Investigation, vol. 121, no. 5, pp. 1894-1904, 2011.

[139] F. Limana, C. Bertolami, A. Mangoni et al., "Myocardial infarction induces embryonic reprogramming of epicardial c-kit(+) cells: role of the pericardial fluid," Journal of Molecular and Cellular Cardiology, vol. 48, no. 4, pp. 609-618, 2010.

[140] A. C. Gittenberger-de Groot, E. M. Winter, and R. E. Poelmann, "Epicardium-derived cells (EPDCs) in development, cardiac disease and repair of ischemia," Journal of Cellular and Molecular Medicine, vol. 14, no. 5, pp. 1056-1060, 2010.

[141] A. Lepilina, A. N. Coon, K. Kikuchi et al., “A dynamic epicardial injury response supports progenitor cell activity during zebrafish heart regeneration," Cell, vol. 127, no. 3, pp. 607-619, 2006.

[142] H. Lie-Venema, N. M. S. van den Akker, N. A. M. Bax et al., "Origin, fate, and function of epicardium-derived cells (EPDCs) in normal and abnormal cardiac development," Scientific World Journal, vol. 7, pp. 1777-1798, 2007.

[143] A. Wessels and J. M. Perez-Pomares, "The epicardium and epicardially derived cells (EPDCs) as cardiac stem cells," The Anatomical Record Part A, Discoveries in Molecular, Cellular, and Evolutionary Biology, vol. 276, no. 1, pp. 4357, 2004.

[144] S. Bollini, N. Smart, and P. R. Riley, "Resident cardiac progenitor cells: at the heart of regeneration," Journal of Molecular and Cellular Cardiology, vol. 50, no. 2, pp. 296-303, 2011.

[145] T. H. P. Chen, T.-C. Chang, J.-O. Kang et al., "Epicardial induction of fetal cardiomyocyte proliferation via a retinoic acid-inducible trophic fact," Developmental Biology, vol. 250, no. 1, pp. 198-207, 2002. 
[146] E. M. Winter, A. A. M. Van Oorschot, B. Hogers et al., "A new direction for cardiac regeneration therapy: application of synergistically acting epicardium-derived cells and cardiomyocyte progenitor cells," Circulation Heart Failure, vol. 2, no. 6, pp. 643-653, 2009.

[147] L. M. Popescu and M.-S. Faussone-Pellegrini, “Telocytes - a case of serendipity: the winding way from interstitial cells of Cajal (ICC), via interstitial Cajal-like cells (ICLC) to telocytes," Journal of Cellular and Molecular Medicine, vol. 14, no. 4, pp. 729-740, 2010.

[148] M. Gherghiceanu and L. M. Popescu, "Cardiomyocyte precursors and telocytes in epicardial stem cell niche: electron microscope images," Journal of Cellular and Molecular Medicine, vol. 14, no. 4, pp. 871-877, 2010.

[149] L. M. Popescu, E. T. Fertig, and M. Gherghiceanu, "Reaching out: junctions between cardiac telocytes and cardiac stem cells in culture," Journal of Cellular and Molecular Medicine, vol. 20, no. 2, pp. 370-380, 2016.

[150] Y. Bei, F. Wang, C. Yang, and J. Xiao, “Telocytes in regenerative medicine," Journal of Cellular and Molecular Medicine, vol. 19, no. 7, pp. 1441-1454, 2015.

[151] D. Bani, L. Formigli, M. Gherghiceanu, and M. S. FaussonePellegrini, "Telocytes as supporting cells for myocardial tissue organization in developing and adult heart," Journal of Cellular and Molecular Medicine, vol. 14, no. 10, pp. 25312538, 2010.

[152] C. G. Manole, V. Cismasiu, M. Gherghiceanu, and L. M. Popescu, "Experimental acute myocardial infarction: telocytes involvement in neo-angiogenesis," Journal of Cellular and Molecular Medicine, vol. 15, no. 11, pp. 2284-2296, 2011.

[153] V. B. Cismasiu, E. Radu, and L. M. Popescu, "miR-193 expression differentiates telocytes from other stromal cells," Journal of Cellular and Molecular Medicine, vol. 15, no. 5, pp. 1071-1074, 2011.

[154] G. Luxán, G. D’Amato, D. MacGrogan, and J. L. de la Pompa, "Endocardial notch signaling in cardiac development and disease," Circulation Research, vol. 118, no. 1, pp. e1-e18, 2016.

[155] K. Niessen and A. Karsan, "Notch signaling in cardiac development," Circulation Research, vol. 102, no. 10, pp. 11691181, 2008.

[156] J. L. De la Pompa and J. A. Epstein, "Coordinating tissue interactions: notch signaling in cardiac development and disease," Developmental Cell, vol. 22, no. 2, pp. 244-254, 2012.

[157] A. Boni, K. Urbanek, A. Nascimbene et al., "Notch1 regulates the fate of cardiac progenitor cells," Proceedings of the National Academy of Sciences of the United States of America, vol. 105, no. 40, pp. 15529-15534, 2008.

[158] C. Kwon, L. Qian, P. Cheng, V. Nigam, J. Arnold, and D. Srivastava, "A regulatory pathway involving Notch1/ beta-catenin/Isl1 determines cardiac progenitor cell fate," Nature Cell Biology, vol. 11, no. 8, pp. 951-957, 2009.

[159] N. Gude and M. Sussman, "Notch signaling and cardiac repair," Journal of Molecular and Cellular Cardiology, vol. 52, no. 6, pp. 1226-1232, 2012.

[160] C. Collesi, L. Zentilin, G. Sinagra, and M. Giacca, "Notch1 signaling stimulates proliferation of immature cardiomyocytes," The Journal of Cell Biology, vol. 183, no. 1, pp. 117-128, 2008.

[161] E. Øie, W. J. Sandberg, M. S. Ahmed et al., "Activation of notch signaling in cardiomyocytes during post-infarction remodeling," Scandinavian Cardiovascular Journal, vol. 44, no. 6, pp. 359-366, 2010.
[162] N. A. Gude, G. Emmanuel, W. Wu et al., "Activation of notch-mediated protective signaling in the myocardium," Circulation Research, vol. 102, no. 9, pp. 1025-1035, 2008.

[163] P. Kratsios, C. Catela, E. Salimova et al., "Distinct roles for cell-autonomous notch signaling in cardiomyocytes of the embryonic and adult heart," Circulation Research, vol. 106, no. 3, pp. 559-572, 2010.

[164] B. Yu and B. Song, "Notch 1 signalling inhibits cardiomyocyte apoptosis in ischaemic postconditioning," Heart, Lung and Circulation, vol. 23, no. 2, pp. 152-158, 2014.

[165] P. Rizzo, D. Mele, C. Caliceti et al., "The role of notch in the cardiovascular system: potential adverse effects of investigational notch inhibitors," Frontiers in Oncology, vol. 4, p. 384, 2014.

[166] M. Mazzone, L. M. Selfors, J. Albeck et al., "Dose-dependent induction of distinct phenotypic responses to Notch pathway activation in mammary epithelial cells," Proceedings of the National Academy of Sciences of the United States of America, vol. 107, no. 11, pp. 5012-5017, 2010.

[167] M. Guentchev and R. D. G. McKay, "Notch controls proliferation and differentiation of stem cells in a dose-dependent manner," The European Journal of Neuroscience, vol. 23, no. 9, pp. 2289-2296, 2006.

[168] A. V. Boopathy, P. L. Che, I. Somasuntharam et al., "The modulation of cardiac progenitor cell function by hydrogeldependent Notch1 activation," Biomaterials, vol. 35 , no. 28 , pp. 8103-8112, 2014.

[169] J. Günter, P. Wolint, A. Bopp et al., "Microtissues in cardiovascular medicine: regenerative potential based on a 3D microenvironment," Stem Cells International, vol. 2016, Article ID 9098523, 20 pages, 2016.

[170] E. Forte, F. Miraldi, I. Chimenti et al., “TGF $\beta$-dependent epithelial-to-mesenchymal transition is required to generate cardiospheres from human adult heart biopsies," Stem Cells and Development, vol. 21, no. 17, pp. 3081-3090, 2012.

[171] M. A. Rossi, "Connective tissue skeleton in the normal left ventricle and in hypertensive left ventricular hypertrophy and chronic chagasic myocarditis," Medical Science Monitor, vol. 7, pp. 820-832, 2001.

[172] C. Jourdan-Lesaux, J. Zhang, and M. L. Lindsey, "Extracellular matrix roles during cardiac repair," Life Sciences, vol. 87, pp. 391-400, 2010.

[173] Y. Matsui, J. Morimoto, and T. Uede, "Role of matricellular proteins in cardiac tissue remodeling after myocardial infarction," World Journal of Biological Chemistry, vol. 1, no. 5, pp. 69-80, 2010.

[174] B. I. Jugdutt, "Ventricular remodeling after infarction and the extracellular collagen matrix: when is enough enough?," Circulation, vol. 108, no. 11, pp. 1395-1403, 2003.

[175] K. V. T. Engebretsen, A. Waehre, J. L. Bjørnstad et al., "Decorin, lumican, and their GAG chain-synthesizing enzymes are regulated in myocardial remodeling and reverse remodeling in the mouse," Journal of Applied Physiology, vol. 114, no. 8, pp. 988-997, 2013.

[176] K. Imanaka-Yoshida, "Tenascin-C in cardiovascular tissue remodeling," Circulation Journal, vol. 76, no. 11, pp. 25132520, 2012.

[177] G. R. Martin and R. Timpl, "Laminin and other basement membrane components," Annual Review of Cell Biology, vol. 3, pp. 57-85, 1987. 
[178] S. Corda, J. L. Samuel, and L. Rappaport, "Extracellular matrix and growth factors during heart growth," Heart Failure Reviews, vol. 5, no. 2, pp. 119-130, 2000.

[179] P. Carmeliet and R. K. Jain, "Molecular mechanisms and clinical applications of angiogenesis," Nature, vol. 473, no. 7347, pp. 298-307, 2011.

[180] D. I. Bromage, S. M. Davidson, and D. M. Yellon, "Stromal derived factor $1 \alpha$ : a chemokine that delivers a two-pronged defence of the myocardium," Pharmacology \& Therapeutics, vol. 143, no. 3, pp. 305-315, 2014.

[181] K. E. Porter and N. A. Turner, "Cardiac fibroblasts: at the heart of myocardial remodeling," Pharmacology \& Therapeutics, vol. 123, pp. 255-278, 2009.

[182] S. Israeli-Rosenberg, A. M. Manso, H. Okada, and R. S. Ross, "Integrins and integrin-associated proteins in the cardiac myocyte," Circulation Research, vol. 114, no. 3, pp. 572-586, 2014.

[183] N. J. Merna, K. M. Fung, J. J. Wang et al., "Differential $\beta 3$ integrin expression regulates the response of human lung and cardiac fibroblasts to extracellular matrix and its components," Tissue Engineering Part A, vol. 21, pp. 1-11, 2015.

[184] A. Mauretti, N. A. M. Bax, M. H. van Marion, M. J. Goumans, C. Sahlgren, and C. V. C. Bouten, "Cardiomyocyte progenitor cell mechanoresponse unrevealed: strain avoidance and mechanosome development," Integrative Biology, vol. 8, no. 9, pp. 991-1001, 2016.

[185] B. D. Cosgrove, K. L. Mui, T. P. Driscoll et al., "Role of extracellular matrix signaling cues in modulating cell fate commitment for cardiovascular tissue engineering," Advanced Healthcare Materials, vol. 3, no. 5, pp. 628-641, 2016.

[186] K. M. French, A. V. Boopathy, J. A. Dequach et al., "A naturally derived cardiac extracellular matrix enhances cardiac progenitor cell behavior in vitro," Acta Biomaterialia, vol. 8, no. 12, pp. 4357-4364, 2012.

[187] R. Gaetani, C. Yin, N. Srikumar et al., "Cardiac derived extracellular matrix enhances cardiogenic properties of human cardiac progenitor cells," Cell Transplantation, vol. 25, no. 858, pp. 1653-1663, 2015.

[188] K. M. French, J. T. Maxwell, S. Bhutani et al., "Fibronectin and cyclic strain improve cardiac progenitor cell regenerative potential in vitro," Stem Cells International, vol. 2016, Article ID 8364382, 11 pages, 2016.

[189] M. H. Konstandin, H. Toko, G. M. Gastelum et al., "Fibronectin is essential for reparative cardiac progenitor cell response after myocardial infarction," Circulation Research, vol. 113, no. 2, pp. 115-125, 2013.

[190] C. Williams, E. Budina, W. L. Stoppel et al., "Cardiac extracellular matrix-fibrin hybrid scaffolds with tunable properties for cardiovascular tissue engineering," Acta Biomaterialia, vol. 14, pp. 84-95, 2015.

[191] M. Tallawi, R. Rai, A. R. Boccaccini, and K. Aifantis, "Effect of substrate mechanics on cardiomyocyte maturation and growth," Tissue Engineering Part B, Reviews, vol. 21, no. 1, pp. 157-165, 2014.

[192] J. L. Young and A. J. Engler, "Hydrogels with time-dependent material properties enhance cardiomyocyte differentiation in vitro," Biomaterials, vol. 32, no. 4, pp. 1002-1009, 2011.

[193] M. Y. Choi, J. T. Kim, W. J. Lee et al., "Engineered extracellular microenvironment with a tunable mechanical property for controlling cell behavior and cardiomyogenic fate of cardiac stem cells," Acta Biomaterialia, vol. 50, pp. 234-248, 2017.
[194] J. A. Hannafin, E. A. Attia, R. Henshaw, R. F. Warren, and M. M. Bhargava, "Effect of cyclic strain and plating matrix on cell proliferation and integrin expression by ligament fibroblasts," Journal of Orthopaedic Research, vol. 24, no. 2, pp. 149-158, 2006.

[195] H. E. Balcioglu, H. van Hoorn, D. M. Donato, T. Schmidt, and E. H. J. Danen, "The integrin expression profile modulates orientation and dynamics of force transmission at cellmatrix adhesions," Journal of Cell Science, vol. 128, no. 7, pp. 1316-1326, 2015.

[196] M. H. van Marion, N. A. M. Bax, M. C. van Turnhout et al., "Behavior of CMPCs in unidirectional constrained and stress-free 3D hydrogels," Journal of Molecular and Cellular Cardiology, vol. 87, pp. 79-91, 2015.

[197] A. Mohyeldin, T. Garzón-Muvdi, and A. Quiñones-Hinojosa, "Oxygen in stem cell biology: a critical component of the stem cell niche," Cell Stem Cell, vol. 7, no. 2, pp. 150-161, 2010.

[198] B. Keith and M. C. Simon, "Hypoxia-inducible factors, stem cells, and cancer," Cell, vol. 129, no. 3, pp. 465-472, 2007.

[199] M. V. Gustafsson, X. Zheng, T. Pereira et al., "Hypoxia requires Notch signaling to maintain the undifferentiated cell state," Developmental Cell, vol. 9, no. 5, pp. 617-628, 2005.

[200] J. M. Adams, L. T. Difazio, R. H. Rolandelli et al., "HIF-1: a key mediator in hypoxia," Acta Physiologica Hungarica, vol. 96, no. 1, pp. 19-28, 2009.

[201] J. S. Jurgensen, C. Rosenberger, M. S. Wiesener et al., "Persistent induction of HIF-1alpha and -2alpha in cardiomyocytes and stromal cells of ischemic myocardium," The FASEB Journal, vol. 18, no. 12, pp. 1415-1417, 2004.

[202] D. J. Ceradini, A. R. Kulkarni, M. J. Callaghan et al., "Progenitor cell trafficking is regulated by hypoxic gradients through HIF-1 induction of SDF-1," Nature Medicine, vol. 10, no. 8, pp. 858-864, 2004.

[203] P. Staller, J. Sulitkova, J. Lisztwan, H. Moch, E. J. Oakeley, and W. Krek, "Chemokine receptor CXCR4 downregulated by von Hippel-Lindau tumour suppressor pVHL," Nature, vol. 425, no. 6955, pp. 307-311, 2003.

[204] A. Zernecke, A. Schober, I. Bot et al., "SDF-1alpha/CXCR4 axis is instrumental in neointimal hyperplasia and recruitment of smooth muscle progenitor cells," Circulation Research, vol. 96, no. 7, pp. 784-791, 2005.

[205] K. Jujo, H. Hamada, A. Iwakura et al., "CXCR4 blockade augments bone marrow progenitor cell recruitment to the neovasculature and reduces mortality after myocardial infarction," Proceedings of the National Academy of Sciences of the United States of America, vol. 107, no. 24, pp. 1100811013, 2010.

[206] H. Zheng, G. Fu, T. Dai, and H. Huang, "Migration of endothelial progenitor cells mediated by stromal cellderived factor-1alpha/CXCR4 via PI3K/Akt/eNOS signal transduction pathway," Journal of Cardiovascular Pharmacology, vol. 50, no. 3, pp. 274-280, 2007.

[207] S. K. Ghadge, S. Muhlstedt, C. Ozcelik, and M. Bader, "SDFlalpha as a therapeutic stem cell homing factor in myocardial infarction," Pharmacology \& Therapeutics, vol. 129, no. 1, pp. 97-108, 2011.

[208] N. Smart and P. R. Riley, "The stem cell movement," Circulation Research, vol. 102, no. 10, pp. 1155-1168, 2008.

[209] Y. L. Tang, W. Zhu, M. Cheng et al., "Hypoxic preconditioning enhances the benefit of cardiac progenitor cell therapy for 
treatment of myocardial infarction by inducing CXCR4 expression," Circulation Research, vol. 104, no. 10, pp. 1209-1216, 2009.

[210] D. Chen, Y. Xia, K. Zuo et al., "Crosstalk between SDF-1/ CXCR4 and SDF-1/CXCR7 in cardiac stem cell migration," Scientific Reports, vol. 5, article 16813, 2015.

[211] A. A. M. van Oorschot, A. M. Smits, E. Pardali, P. A. Doevendans, and M.-J. Goumans, "Low oxygen tension positively influences cardiomyocyte progenitor cell function," Journal of Cellular and Molecular Medicine, vol. 15, no. 12, pp. 2723-2734, 2011.

[212] D. J. Ceradini and G. C. Gurtner, "Homing to hypoxia: HIF-1 as a mediator of progenitor cell recruitment to injured tissue," Trends in Cardiovascular Medicine, vol. 15, no. 2, pp. 57-63, 2005.

[213] T.-M. Achilli, J. Meyer, and J. R. Morgan, "Advances in the formation, use and understanding of multi-cellular spheroids," Expert Opinion on Biological Therapy, vol. 12, no. 10, pp. 1347-1360, 2012.

[214] Y. Li, Y. Hiroi, and J. K. Liao, "Notch signaling as an important mediator of cardiac repair and regeneration after myocardial infarction," Trends in Cardiovascular Medicine, vol. 20, no. 7, pp. 228-231, 2010.

[215] F. Gattazzo, A. Urciuolo, and P. Bonaldo, "Extracellular matrix: a dynamic microenvironment for stem cell niche," Biochimica et Biophysica Acta (BBA) - General Subjects, vol. 1840, no. 8, pp. 2506-2519, 2014.

[216] E. Cambria, J. Steiger, J. Günter et al., "Cardiac regenerative medicine: the potential of a new generation of stem cells," Transfusion Medicine and Hemotherapy, vol. 43, no. 4, pp. 275-281, 2016.

[217] S. Pok, J. D. Myers, S. V. Madihally, and J. G. Jacot, "A multilayered scaffold of a chitosan and gelatin hydrogel supported by a PCL core for cardiac tissue engineering," Acta Biomaterialia, vol. 9, no. 3, pp. 5630-5642, 2013.

[218] T. D. Johnson, J. A. Dequach, R. Gaetani et al., "Human versus porcine tissue sourcing for an injectable myocardial matrix hydrogel," Biomaterials Science, vol. 2014, article 60283D, 2014.

[219] R. Gaetani, P. A. Doevendans, C. H. Metz et al., "Cardiac tissue engineering using tissue printing technology and human cardiac progenitor cells," Biomaterials, vol. 33, no. 6, pp. 1782-1790, 2012.

[220] T. C. K. Liu, S. Ismail, O. Brennan, C. Hastings, and G. P. Duffy, "Encapsulation of cardiac stem cells in superoxide dismutase-loaded alginate prevents doxorubicin-mediated toxicity," Journal of Tissue Engineering and Regenerative Medicine, vol. 7, no. 4, pp. 302-311, 2013.

[221] J. Leor, Y. Amsalem, and S. Cohen, "Cells, scaffolds, and molecules for myocardial tissue engineering," Pharmacology \& Therapeutics, vol. 105, no. 2, pp. 151-163, 2005.

[222] K. Cheng, D. Shen, J. Smith et al., "Transplantation of platelet gel spiked with cardiosphere-derived cells boosts structural and functional benefits relative to gel transplantation alone in rats with myocardial infarction," Biomaterials, vol. 33, no. 10, pp. 2872-2879, 2012.

[223] M. Tiburcy, J. E. Hudson, P. Balfanz et al., "Defined engineered human myocardium with advanced maturation for applications in heart failure modelling and repair," Circulation, vol. 135, no. 19, pp. 1832-1847, 2017.
[224] S. S. Nunes, J. W. Miklas, J. Liu et al., "Biowire: a platform for maturation of human pluripotent stem cell-derived cardiomyocytes," Nature Methods, vol. 10, no. 8, pp. 781-787, 2013.

[225] N. L. Tulloch, V. Muskheli, M. V. Razumova et al., "Growth of engineered human myocardium with mechanical loading and vascular coculture," Circulation Research, vol. 109, no. 1, pp. 47-59, 2011.

[226] D. Zhang, I. Y. Shadrin, J. Lam, H. Q. Xian, H. R. Snodgrass, and N. Bursac, "Tissue-engineered cardiac patch for advanced functional maturation of human ESC-derived cardiomyocytes," Biomaterials, vol. 34, no. 23, pp. 5813-5820, 2013.

[227] E. Ghafar-Zadeh, J. R. Waldeisen, and L. P. Lee, "Engineered approaches to the stem cell microenvironment for cardiac tissue regeneration," Lab on a Chip, vol. 11, no. 18, pp. 30313048, 2011.

[228] D. E. Discher, D. J. Mooney, and P. W. Zandstra, "Growth factors, matrices, and forces combine and control stem cells," Science, vol. 324, no. 5935, pp. 1673-1677, 2009.

[229] D. E. Discher, P. Janmey, and Y.-L. Wang, "Tissue cells feel and respond to the stiffness of their substrate," Science, vol. 310, no. 5751, pp. 1139-1143, 2005.

[230] A. M. Throm Quinlan, L. N. Sierad, A. K. Capulli, L. E. Firstenberg, and K. L. Billiar, "Combining dynamic stretch and tunable stiffness to probe cell mechanobiology in vitro," PLoS One, vol. 6, no. 8, article e23272, 2011.

[231] N. Tandon, C. Cannizzaro, P.-H. G. Chao et al., "Electrical stimulation systems for cardiac tissue engineering," Nature Protocols, vol. 4, no. 2, pp. 155-173, 2009.

[232] B. Murtuza, J. W. Nichol, and A. Khademhosseini, "Microand nanoscale control of the cardiac stem cell niche for tissue fabrication," Tissue Engineering Part B, vol. 15, no. 4, pp. 443-454, 2009.

[233] C. Morez, M. Noseda, M. A. Paiva, E. Belian, M. D. Schneider, and M. M. Stevens, "Enhanced efficiency of genetic programming toward cardiomyocyte creation through topographical cues," Biomaterials, vol. 70, pp. 94-104, 2015. 

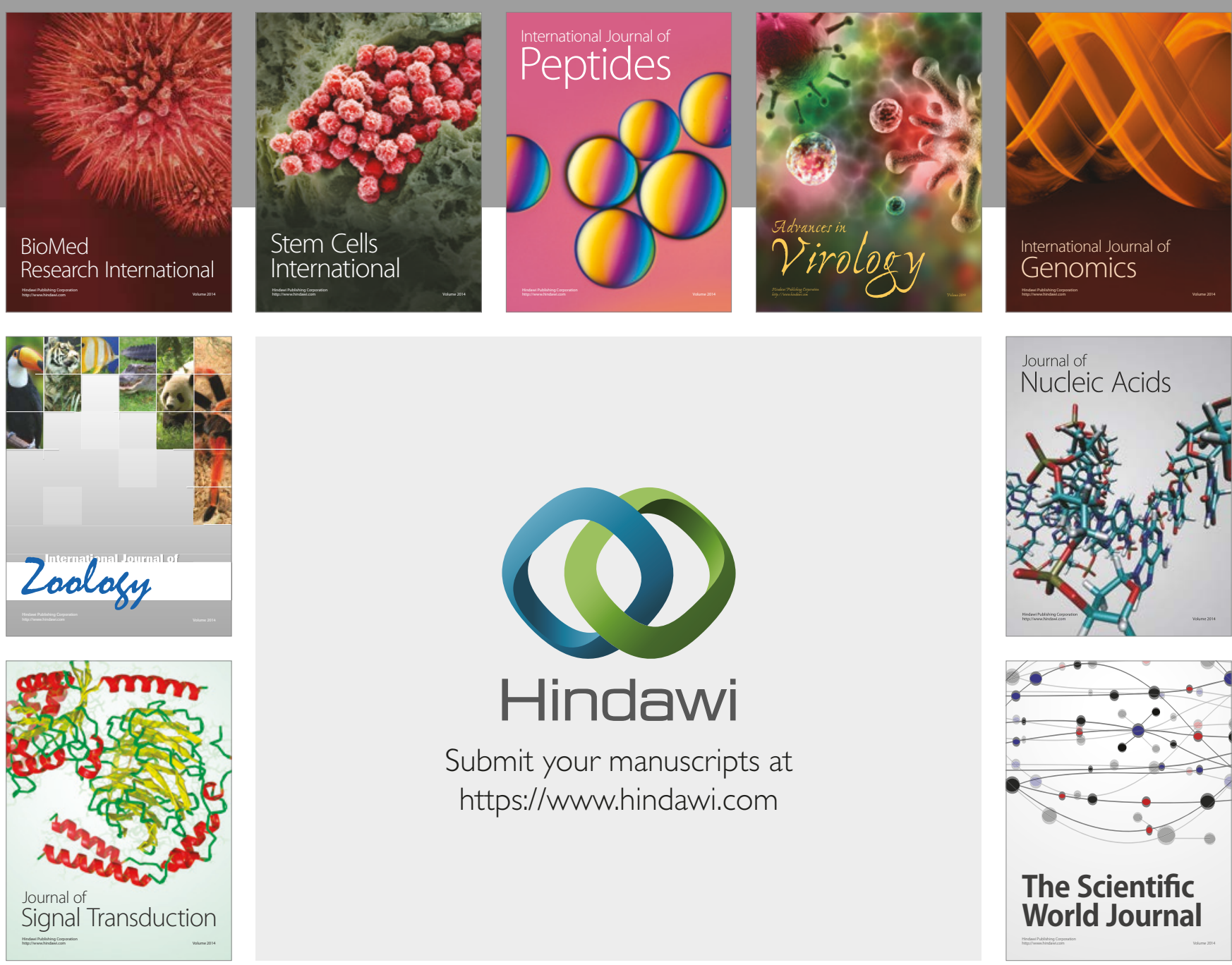

Submit your manuscripts at

https://www.hindawi.com
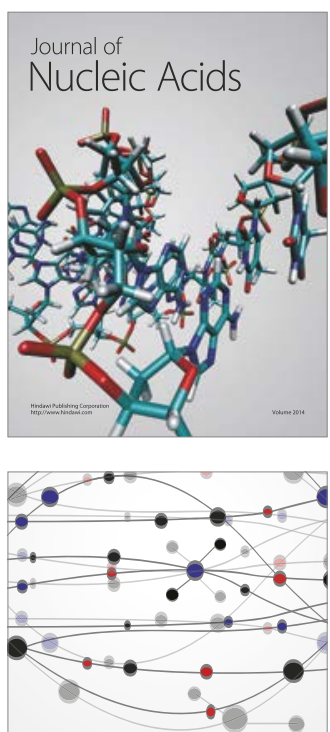

The Scientific World Journal

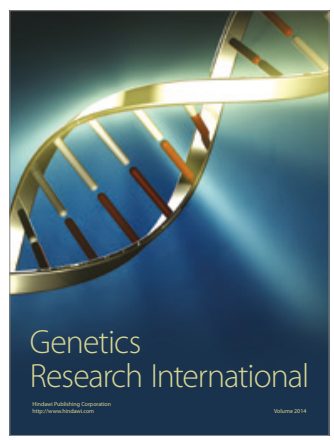

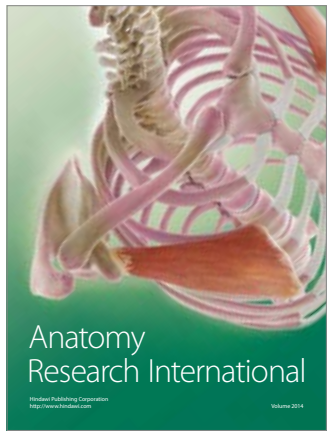

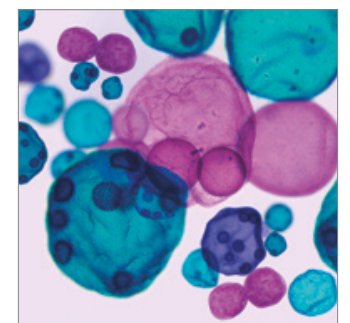

International Journal of Microbiology
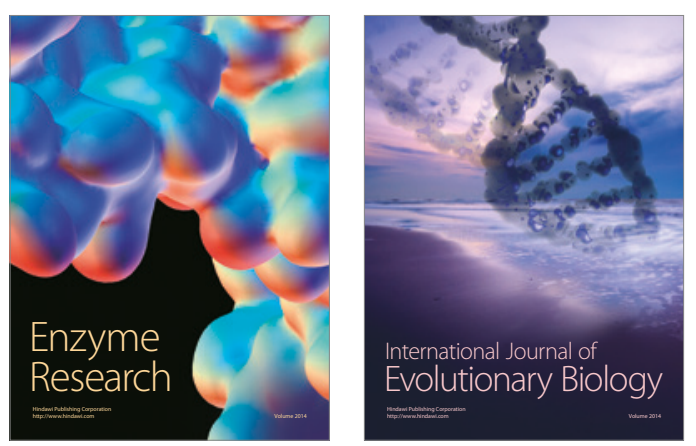
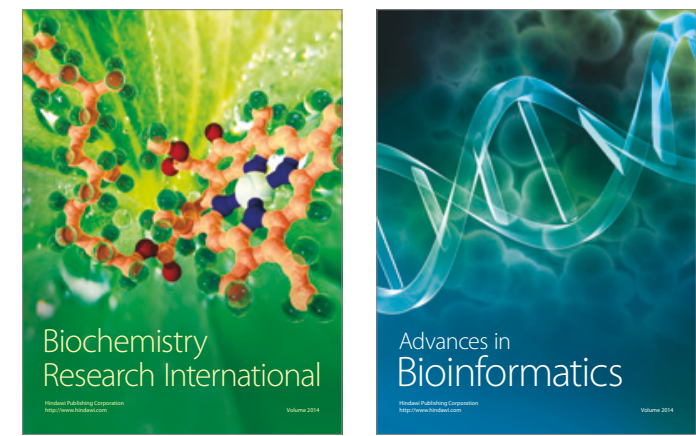

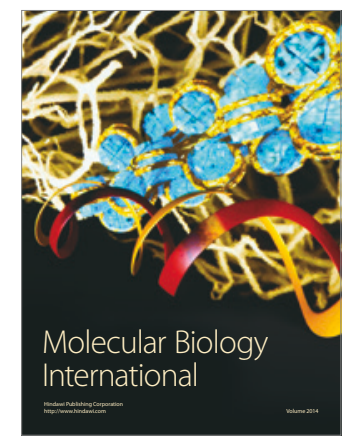

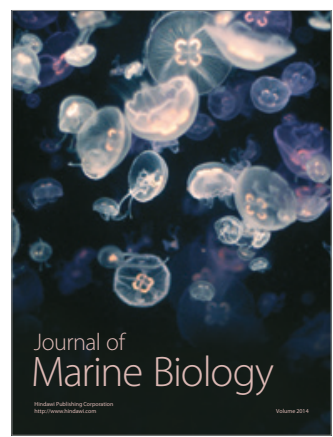

